MISCELLANEOUS PUBLICATIONS

MUSEUM OF ZOOLOGY, UNIVERSITY OF MICHIGAN, NO. 136

\title{
The Biology of the Elf Owl, Micrathene whitneyi
}

BY

J. DAVID LIGON

\author{
ANN Arbor \\ MUSEUM OF ZOOLOGY, UNIVERSITY OF MICHIGAN \\ FEBRUARY 27, 1968
}




\section{MISCELLANEOUS PUBLICATIONS MUSEUM OF ZOOLOGY, UNIVERSITY OF MICHIGAN}

William H. BURT, EdTTOR

Robert W. Storer, Associate Editor

The publications of the Museum of Zoology, University of Michigan, consist of two series-the Occasional Papers and the Miscellaneous Publications. Both series were founded by Dr. Bryant Walker, Mr. Bradshaw H. Swales, and Dr. W. W. Newcomb.

The Occasional Papers, publication of which was begun in 1913, serve as a medium for original studies based principally upon the collections in the Museum. They are issued separately. When a sufficient number of pages has been printed to make a volume, a title page, table of contents, and an index are supplied to libraries and individuals on the mailing list for the series.

The Miscellaneous Publications, which include papers on field and museum techniques, monographic studies, and other contributions not within the scope of the Occasional Papers, are published separately. It is not intended that they be grouped into volumes. Each number has a title page and, when necessary, a table of contents.

A complete list of publications on Birds, Fishes, Insects, Mammals, Mollusks, and Reptiles and Amphibians is available. Address inquiries to the Director, Museum of Zoology, Ann Arbor, Michigan 48104.

\section{List of Miscellaneous Publications on Birds}

No. 10. A preliminary survey of the bird life of North Dakota. By Norman A. Wood. (1923) 96 pp., 6 pls. 1 map .....................

No. 19. The life history of the toucan Ramphastos brevicarinatus. By Josselyn VAN Trne. (1929) 43 pp., 8 pls., 1 map .....................

No. 27. The birds of northern Petén, Guatemala. By Josselyn VAN TyNe. (1935) 46 pp., frontis., 1 pl., 1 map ............................

No. 33. The discovery of the nest of the Colima warbler (Vermivora crissalis). By JosseYlN VAN TyNe. (1936) 11 pp., colored frontis., 3 pls., 1 map ..

No. 37. The birds of Brewster County, Texas. By Josselyn VAN TyNe and GeORGE Mirsch Sutron. (1937) 119 pp., colored frontis., 5 pls., 1 map ....

No. 41. The life history of Henslow's sparrow, Passerherbulus henslowi (Audubon). By A. Sidney Hyde. (1939) 72 pp., 4 pls., 3 figs., 1 map .........

No. 44. The birds of Buckeye Lake, Ohio. By Mrlton B. Trautman. (1940) 466 pp., frontis., 15 pls., 2 maps .........................

No. 55. Birds from the Gulf lowlands of Southern Mexico. By PIERCE Brodkorb.

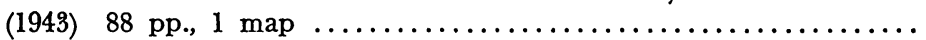

No. 74. Studies of the nesting birds of the Edwin S. George Reserve. Part I. The vireos. By Grorge M. Sutton. (1949) 37 pp., 5 pls. .............

No. 75. The birds of Michigan. By Norman A. Wood. (1951) 559 pp., 16 pls.,

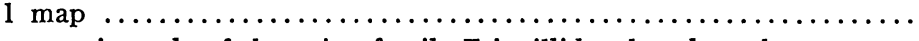

No. 81. A systematic study of the avian family Fringillidae, based on the structure of the skull. By Harrison B. Tordoff. (1954) 42 pp., 77 figs. ......

No. 85. The myology of the pectoral appendage of three genera of American cuckoos. By ANdrew J. Berger. (1954) 35 pp., 4 figs. ............

No. 102. Great blue heron: behavior at the nest By W. Powell Cotrrille and Betty Darling Cottrille. (1958) 15 pp., 7 figs. ..............

No. 125. The breeding biology of the Acadian flycatcher. By Russell E. Mumford.

$(1964) 50 \mathrm{pp} .$, frontis., $1 \mathrm{pl} . \ldots \ldots \ldots \ldots \ldots \ldots \ldots \ldots \ldots \ldots \ldots \ldots \ldots \ldots \ldots \ldots$
No. 136. The biology of the elf owl, Micrathene whitneyi. By J. DAvid Ligon. 
MISCELLANEOUS PUBLICATIONS

MUSEUM OF ZOOLOGY, UNIVERSITY OF MICHIGAN, NO. 136

\section{The Biology of the Elf Owl, Micrathene whitneyi}

$\mathrm{BY}$

J. DAVID LIGON

AnN Arbor

MUSEUM OF ZOOLOGY, UNIVERSITY OF MICHIGAN

FEBRUARy 27, 1968 



\section{CONTENTS}

PAGE

ACKNOWLEdGMENTS $\ldots \ldots \ldots \ldots \ldots \ldots \ldots \ldots \ldots \ldots \ldots \ldots \ldots \ldots \ldots \ldots \ldots \ldots$

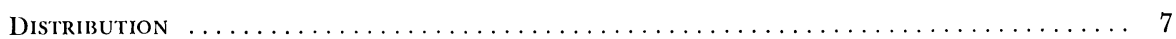

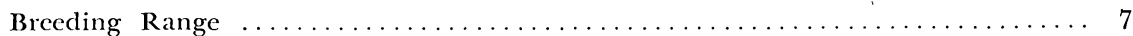

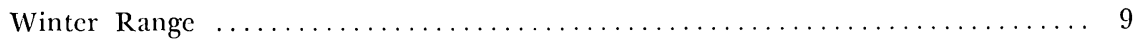

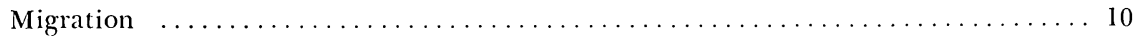

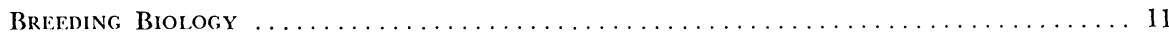

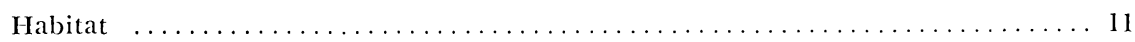

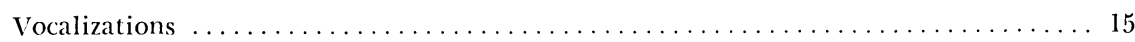

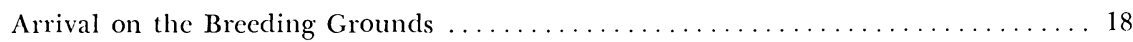

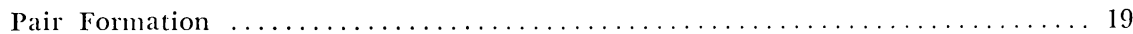

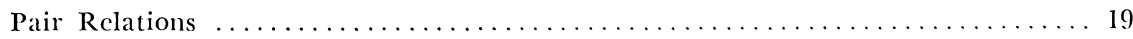

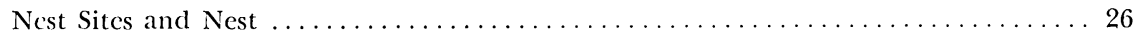

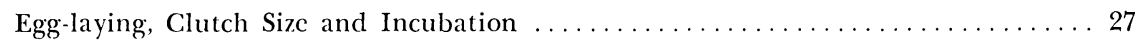

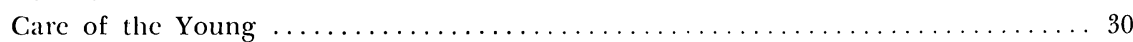

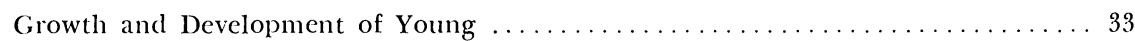

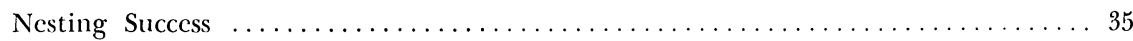

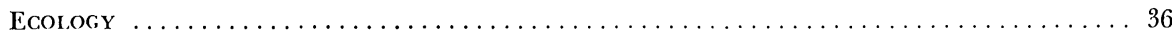

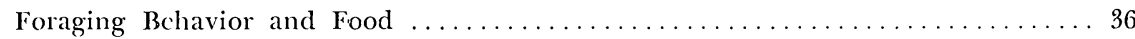

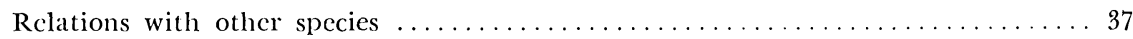

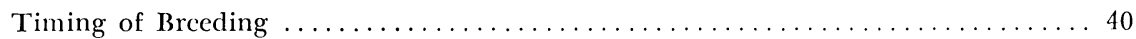

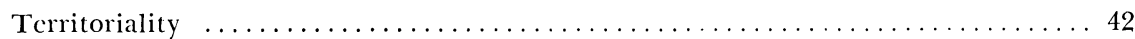

Metabolism and Temperature Regulation $\ldots \ldots \ldots \ldots \ldots \ldots \ldots \ldots \ldots \ldots \ldots \ldots \ldots 48$

Measurements of Microclimate and Body Temperature in Nature . . . . . . . 48

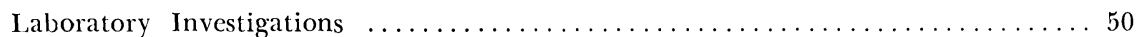

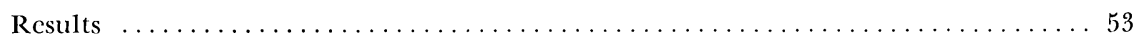

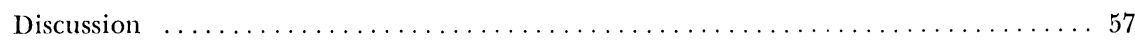

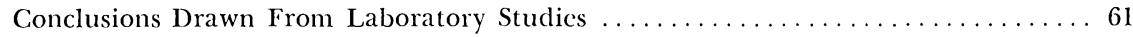

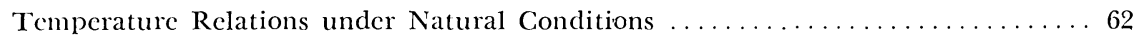

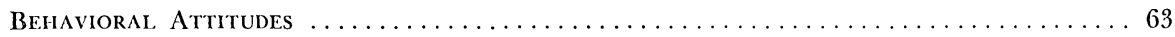

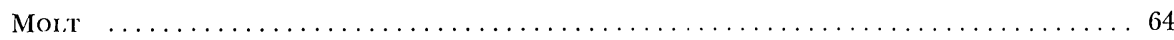

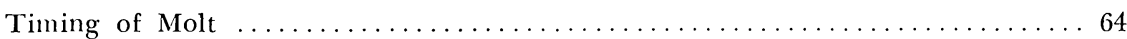

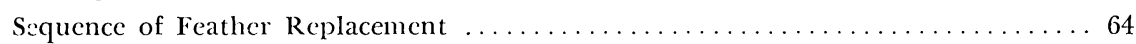

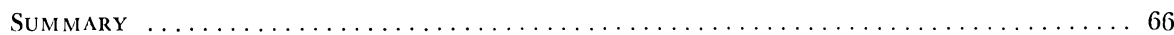

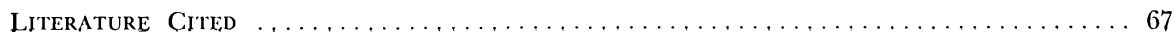




\section{ILLUSTRATIONS}

FIGURE

PAGE

1. Breeding records of the Elf Owl in Mexico $\ldots \ldots \ldots \ldots \ldots \ldots \ldots \ldots$

2. Winter and migrant records of the Elf Owl $\ldots \ldots \ldots \ldots \ldots \ldots \ldots \ldots \ldots \ldots$

3. Canon de Lobos, Morelos, Mexico and, Elf Owl habitat near Rijo, Puebla . . . 12

4. Cave Creek, Chiricahua Mountains, Arizona and, Oak-covered hillside in Cave

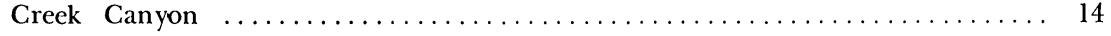

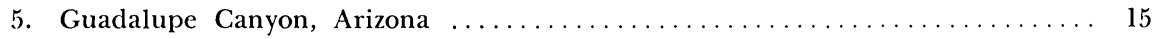

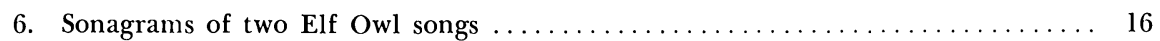

7. Rates of feeding a brood of two nestling Elf Owls $\ldots \ldots \ldots \ldots \ldots \ldots \ldots \ldots \ldots$

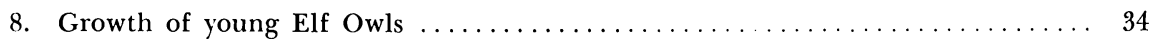

9. Date of laying first egg, for two years $\ldots \ldots \ldots \ldots \ldots \ldots \ldots \ldots \ldots \ldots \ldots \ldots$

10. Territories of two pairs of Elf Owls $\ldots \ldots \ldots \ldots \ldots \ldots \ldots \ldots \ldots \ldots \ldots \ldots$

11. Territories of three pairs of Elf Owls $\ldots \ldots \ldots \ldots \ldots \ldots \ldots \ldots \ldots \ldots \ldots \ldots$

12. Relation of oxygen consumption by Elf Owls to ambient temperature . . . . 53

13. Body temperature of Elf Owls as a function of ambient temperature . . . . . 54

14. Evaporative water loss as a function of ambient temperature in Elf Owls ... 55

15. Cloacal temperature in the Elf Owl in relation to ambient temperature at a

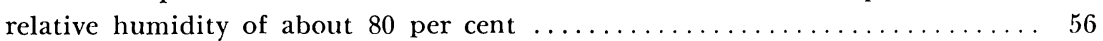

16. Relation between standard metabolic rate and body weight in owls . ..... 57

17. Index of insulation in relation to ambient temperature for four specics of owls 58

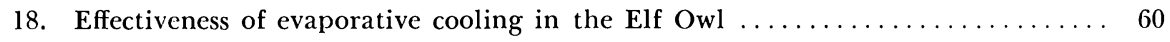

19. The effects of humidity on the initiation of gular flutter in the Elf Owl ... 61

20. The Elf Owl in erect and relaxed postures $\ldots \ldots \ldots \ldots \ldots \ldots \ldots \ldots \ldots \ldots$ 
THE BIOLOGY OF THE ELF OWL, MICRATHENE WHITNEYI

OWls ARE RELATIVEly little known, despite their wide distribution and abundance in many areas, because most species are nocturnal and therefore difficult to study. There is no detailed field study of any New World species of small owl. This investigation of the natural history of the Elf Owl, Micrathene whitneyi, therefore, adds significantly to information available for the group.

The goals of my study were to investigate the field biology and some aspects of the physiological capabilities of the Elf Owl. This species is well suited for behavioral and ecological investigations. In southwestern United States it is often abundant; thus, many nests and individuals can be studied in a single season. Territories are often small, providing opportunities for observations of territorial behavior. Importantly, the Elf Owl is little disturbed either by human presence or by artificial lights; neither normally hinders its activities. I observed foraging, feeding of young, early breeding behavior, and copulation repeatedly with a light trained on the owls. Some of the calls of Elf Owls are sexually diagnostic, and by these one can identify the activities of each member of the pair. Finally, as most activity during the breeding season is in or near nest sites, the location of nests is relatively easy.

Elf Owls are smallest of all owls (adults weigh from 35 to 55 grams); they are almost entirely insectivorous. Over much of their range they inhabit extremely hot, arid areas. This raises a number of intriguing questions, for they neither drink water nor possess any obvious adaptations for survival in desert regions. They live in many habitats, possibly more kinds than any other species of bird in their range. Here they occur in any environment that provides nesting sites and an abundance of insects and other arthropods. They occur in the mountains (in pine-oak woodland up to an altitude of 7000 feet), in the low desert, and in various intermediate habitats.

As a complement to my field studies I investigated physiological responses of Elf Owls to various ambient temperatures in the laboratory. 


\section{ACKNOWLEDGMENTS}

I wish to thank H. B. Tordoff, W. R. Dawson, C. W. Hibbard, and R. W. Storer for critically reviewing the manuscript. W. R. Dawson generously allowed me to use his laboratory facilities. While at the Southwestern Research Station of the American Museum of Natural History I received assistance from the director, V. D. Roth, from R. P. and J. Balda, and from C. R. and J. Sisler. L. W. Walker and J. T. Tanner allowed me to refer to unpublished works. Anne B. Ligon assisted in preparation of the manuscript. J. H. Brown, N. L. Ford, and B. G. Murray, Jr., assisted me in various ways. The Arizona Game and Fish Department allowed me to collect specimens and to transport living birds from Arizona.

Various people provided information concerning specimens. They include J. W. Hardy of the Moore Laboratory of Zoology (abbreviated hereafter as MC) at Occidental College; R. C. Banks, then at the San Diego Natural History Museum; D. Amadon, American Museum of Natural History, N.Y.; N. K. Johnson and D. R. Moore of the University of California Museum of Vertebrate Zoology (MVZ) at Berkeley; E. N. Harrison (ENH); W. C. Jolly, Museum of Comparative Zoology, Harvard; J. Cracraft, then of Louisiana State University Museum of Zoology (LSU); R. L. Zusi of the United States National Museum (USNM); and L. L. Short, Jr. then with the Bureau of Sport Fisheries and Wildlife, Washington, D.C. Special thanks go to A. R. Phillips and R. W. Dickerman for their help and advice during field work in Mexico, and for the use of specimens in Phillips' collection (ARP). Specimens in the University of Michigan Museum of Zoology are designated UMMZ.

I received financial aid from the following sources: United States Public Health Service, Josselyn Van Tyne Memorial Fund of the American Ornithologists' Union, Frank M. Chapman Memorial Fund of the American Museum of Natural History, Edwin C. Hinsdale Scholarship, of the University of Michigan Museum of Zoology, and (in part) by a grant to the University of Michigan from the National Science Foundation for research in Systematic and Evolutionary Biology (NSF No. GB-3366). 


\section{DISTRIBUTION}

BREEDING RANGE

United States.-Elf Owls are widespread in southern Arizona (see map in Phillips et al., 1964:52). They breed also, apparently sporadically, in extreme southeastern California. The first recorded specimens and eggs were taken about 25 miles north of Yuma, Arizona (Brown, 1904). L. Miller (1946) located a breeding pair at Cottonwood Springs, in Joshua Tree National Monument, California. This is apparently the westernmost record of the species.

In New Mexico, the Elf Owl "occupies a zone about 50 to 75 miles wide in the southwestern part of the state adjacent to the Arizona line, from the Mexican border north into the Gila River Valley, where it is not uncommon" (J. S. Ligon, 1961:146).

Elf Owls were first recorded from the Big Bend region, Brewster County, Texas, by Quillin (1935). Van Tyne and Sutton (1937:38) found them breeding in the Basin of the Chisos Mountains and Dixon (1959) recorded one from Brewster County. In extreme southern Texas, in Hidalgo County, Elf Owls presently are common in some areas, particularly in Benson State Park. Their rediscovery there, after a lapse of 70 years, is described by James and Hayse (1963).

Mexico.-The Mexican portions of the breeding ranges given in the American Ornithologists' Union Check-list (1957:283) for the two currently recognized continental races of Elf Owls are misleading and confusing. As Davis (1958) points out, the Check-list indicates that the subspecies Micrathene whitneyi whitneyi breeds in the Mexican states of Guanajuato, Mexico, and Puebla, and that M. $w$. idonea is resident in the same three states. I have been unable to locate evidence of breeding Elf Owls in the states of Guanajuato and Mexico, or in the Federal District. To my knowledge, the only evidence of their presence in these regions is based on the following specimens: Guanajuato, USNM 72888, no date; MC 28421, 26 February, 1941; D.F., MC 36232, 20 February, 1942; and a single specimen from Puebla (USNM 155679), taken on 4 May 1893, which may have been a breeding bird. I searched for Elf Owls in April, 1966, in the Rio Balsas Basin of southern Mexico, investigating the same sites at which they had been found the previous winter (see Winter Range), and located owls only in two areas in Puebla. Figure 1 shows locations of Mexican and Texan breeding records known to me. Also indicated are areas of apparently suitable habitat in which Elf Owls were not found in either season. Speci- 


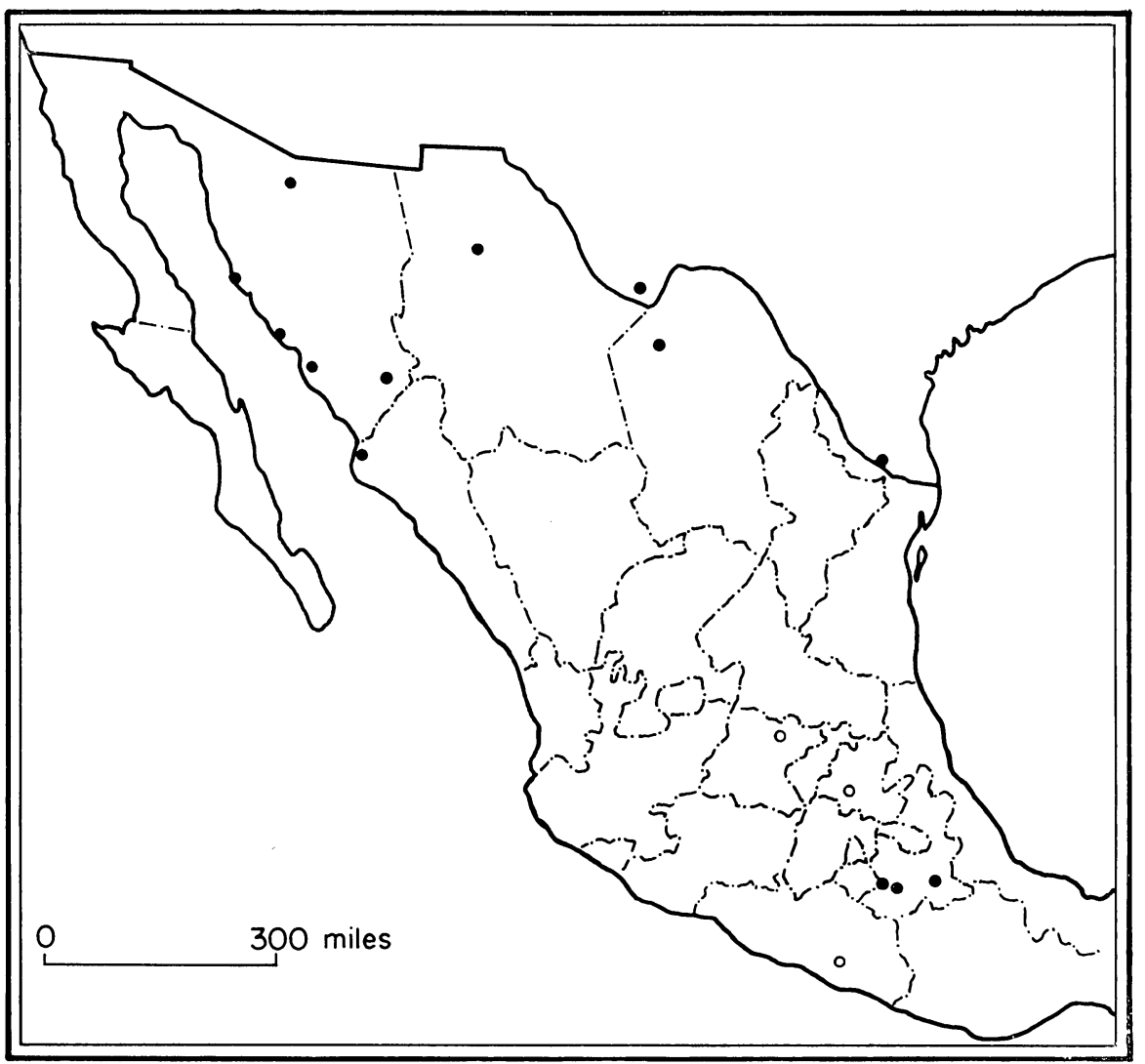

Fic. 1. Breeding records of the Elf Owl in Mexico and Texas, closed circles; areas of apparently suitable habitat where Elf Owls were not found in either winter or spring, open circles.

mens representing Mexican breeding populations include: MVZ 143686, 143687; USNM 155679; ENH 1004, 6988; ARP 1032, 1040, 1041, 1047; LSU 44312, 44313, 44314, 44315; MG 18243; UMMZ 210555, 210556. In addition, A. H. Miller (1955) heard an Elf Owl in Coahuila in April.

The northern portion of the Elf Owl's range appears to contain the highest population densities, although this may in part reflect the greater amount of field work done in that area. In mid-April the population in Puebla appeared to be much less dense than in the areas investigated the previous week in Arizona and southern Texas. The areas in Mexico in which Elf Owls were located in both February and April differed from the places where they were located only in February in having available nest sites in the cactus, Lemaireocereus. The decrease in population from February to April was presumably caused by emigration. 
WINTER RANGE

During the winter months Howell and van Rossem (1915) and Howell (1916) investigated many cavities formerly used by Elf Owls for nesting, but found no birds. Bent (1938:443) stated that the Elf Owl is non-migratory. Phillips (1942) convincingly demonstrated their regular disappearance from Arizona in fall and their reappearance in early spring. He stated that Elf Owls migrate to an unknown winter home. More recently, Phillips et al. (1964:53) stated that the winter range was still virtually unknown, but that it "will probably prove to be the Rio Balsas Basin of southern Mexico."

In January, 1966, in an attempt to determine the winter range of this species, I first investigated cavities in southeastern Arizona which I knew had been used by Elf Owls for nesting the previous summer, and played tape-recorded calls, but found no owls. I then went south into Mexico, playing recordings at night in habitats that appeared to be suitable for Elf Owls. Figure 2 shows winter records I obtained, other winter records, records of probable migrants, and negative records, that is, areas which appeared to be suitable for Elf Owls, but in which none were found. Elf Owls are said to be permanent residents in southern Texas (James and Hayse, 1963), but I found none there in mid-February. Screech Owls (Otus asio), by contrast, were abundant. Specimens representing winter records include: ARP 4636, 6084; MC 54789; MVZ 109737; and UMMZ 210265210270.

The abundance and responsiveness to recordings of birds in areas where they were found and the negative results to the north indicate that the Elf Owl winters in the southernmost portions of the breeding range and is indeed absent from the northern part of its range in winter (Fig. 2). Its winter range thus appears to extend east to northern Oaxaca, west to southwestern Michoacan, north to the edge of the Mexican Plateau, near Cuernavaca, Morelos, and south to the Sierra Madre del Sur, in central Guerrero.

On their winter range the owls apparently roost in a bush or shrubby tree during the day. One, perched in a bush, was taken in Morelos in January by R. W. Dickerman (ARP 6084). In most areas where Elf Owls were found in winter, there were no large trees or cacti to provide cavities suitable for roosting.

The amount of plant cover varied greatly in the areas where wintering owls were found. The vegetation was dense at the base of the Cañon de Lobos (Fig. 3 upper), east of Cuernavaca, Morelos, whereas it was sparse near Rijo, Puebla (Fig. 3 lower). Elf Owls were found on hill tops and slopes as well as in canyon bottoms.

Inasmuch as Elf Owls are nocturnal, they may be forced to winter farther south than if they were diurnal because there appears to be no insect activity 


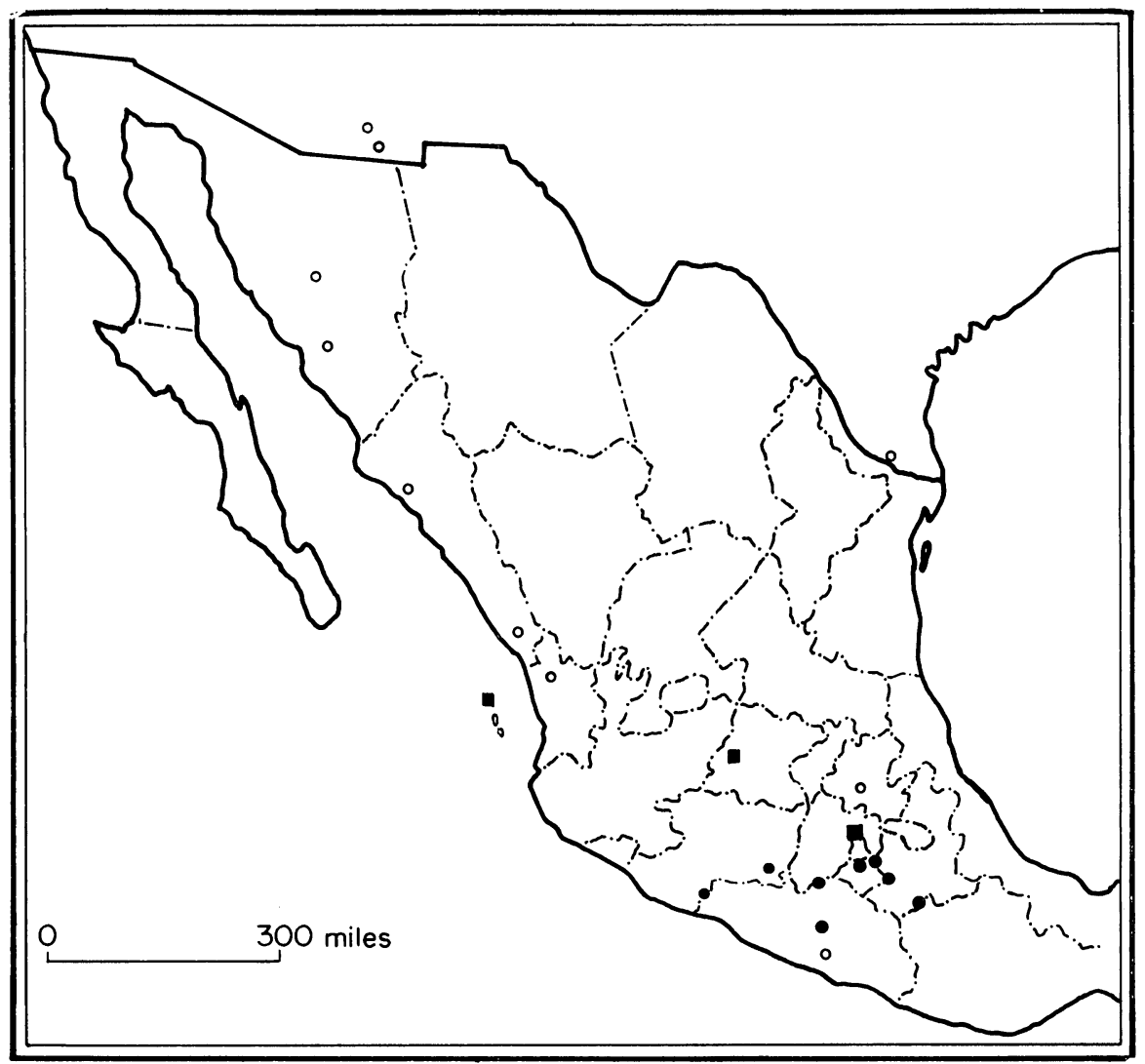

FIG. 2. Winter records, closed circles; negative records, i.e., recordings played in apparently suitable habitat, but no Elf Owls located, open circles; records of probable migrants, squares.

on cold winter nights in southern Arizona. On the Mexican wintering grounds, insects and other arthropods are plentiful at night even though the climate is very dry.

\section{MIGRATION}

Little is known of Elf Owl migration, but some observations indicate that they migrate in large flocks. J. S. Ligon (1961:147) observed numbers of Elf Owls at the entrance of the Gila River Gorge late in the summer of 1918, "sitting on the ground or on rocks beneath the thick scrub bushes of the ledges at [the] base of the canyon wall." Earlier he noted owls roosting in dense cottonwood foliage and mistletoe clusters. Ligon assumed that they had concentrated there prior to migration. A collector for the ArizonaSonora Desert Museum observed a large flock of Elf Owls, perched in trees 
and bushes, in March, at Kino Bay, Sonora (L. W. Walker, oral communication).

Records of specimens that I consider to represent migrants are shown in Figure 2. The two mainland specimens, MC 36232 and 28421, were taken on 20 and 26 February, respectively. Northern (1965) reported one from the Tres Marias Islands.

L. W. Walker (MS) surmises that Elf Owls arrive in Arizona in large flocks; "their journey . . . must be one of massed flight which brings them all into the region together." The observations noted above support this view. Walker bases his conclusion on the fact that the first spring night that Elf Owls are detected by him many are heard. On the other hand, most early spring records provide no evidence that these owls are in flocks. The few individuals that I located in Cave Creek Canyon in the Chiricahua Mountains in early April appeared to be alone. I think that it is more likely that general vocal outbursts by several owls are a result of mutual stimulation. Even wintering birds in Mexico respond to calls of others of their species, and perhaps on one of the first moonlit nights after several Elf Owls have arrived, one bird sings spontaneously and a "chain-reaction" of song is started.

Phillips et al. (1964:53) summarize the status of the Elf Owl in Arizona. The earliest records are 16 and 25 February, and the latest are of two specimens taken on 13 October in the Chiricahua Mountains, Cochise County.

Two other races, $M . w$. sanfordi of Baja California and $M . w$. graysoni of Socorro Island, Revillagigedo Group, presumably are permanent residents.

\section{BREEDING BIOLOGY}

HABITAT

Most of the field work was carried out in Cave Creek Canyon of the Chiricahua Mountains, from 4 to 7 miles southwest of Portal, Arizona. I camped in the canyon from 20 May to 21 July 1964, and observed Elf Owls incidental to other studies. The major portion of the investigations presented here was undertaken 4 May to 4 August 1965, when I stayed at the Southwestern Research Station of the American Museum of Natural History. In 1966 I returned to the station for the periods 2, 3, and 12 April, and 6 to 16,21 to 29 July.

The most conspicuous trees in Cave Creek Canyon are: sycamores (Platanus racemosa), located along the stream beds; alligator juniper (Juniperus deppeana), most common in over-grazed areas; several species of oaks (Quercus); and Apache pine (Pinus engelmanni). Other species are walnuts (Juglans), cottonwoods (Populus), willows (Salix), box elders (Acer), 


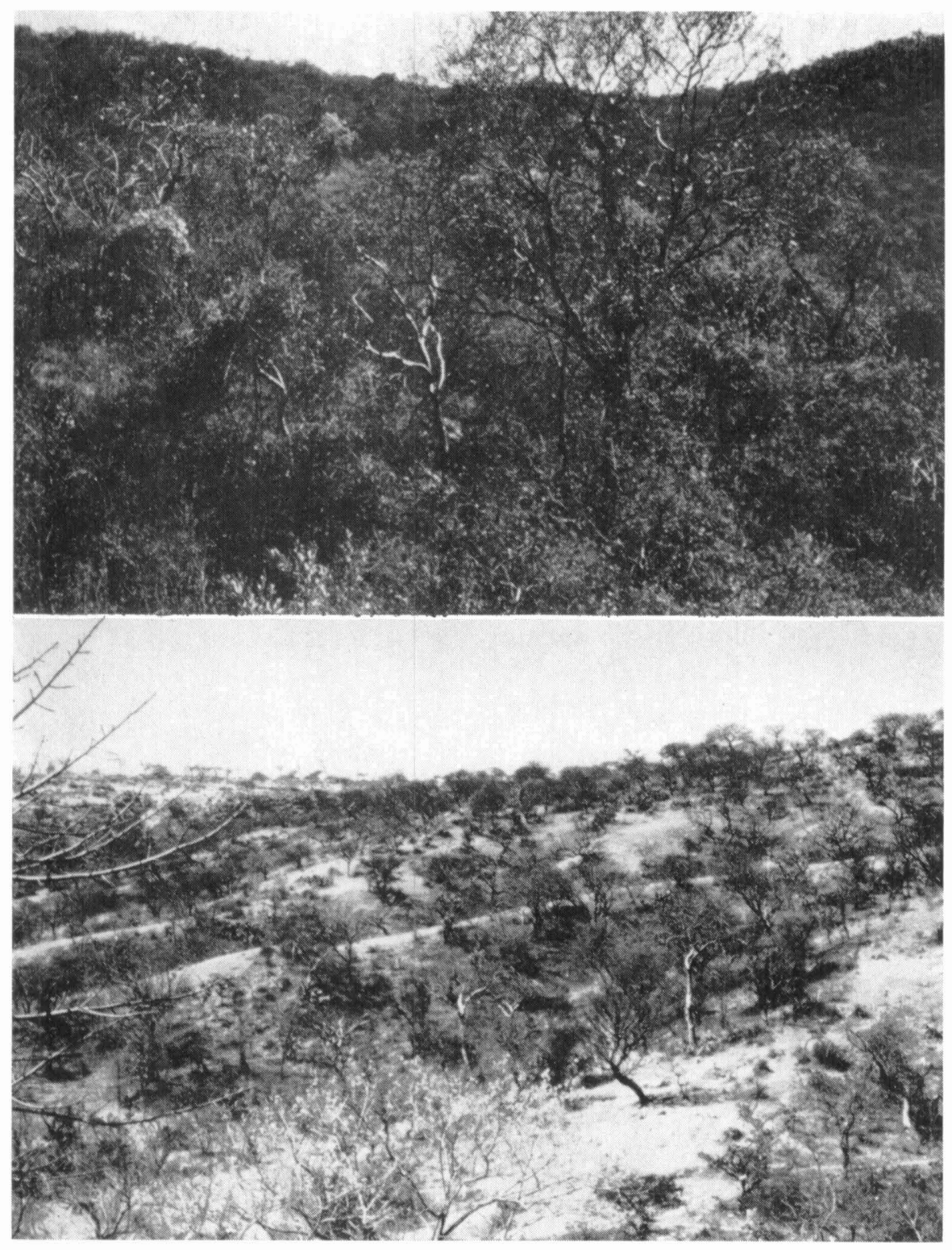

Fig. 3 upper. Cañon de Lobos, Morelos, Mexico. Elf Owls were found here on 28 January 1966.

19 April 1966.

LOWER. Rijo, Puebla. Elf Owls were found here on 7 February and again on 
ash (Fraxinus), and Arizona cypress (Cupressus arizonica). Other plants of the area include Prunus, Vitis, Chrysothamnus, Ceanothus, Senecio, and Rhamnus. Figure 4 illustrates typical Elf Owl breeding and foraging habitat in Cave Creek Canyon.

A summary of temperature and precipitation recorded at the research station for the months of April, May, June, and July 1965 and 1966 is given in Table 1. Rains are highly seasonal in southeastern Arizona, and it is usually extremely dry during April, May, and June. The summer rains typically begin in late June or early July and continue throughout much of August.

\section{TABLE 1}

Chimatological Orservations for Two Years in Cave Creek Canyon (Mcan temperature in parentheses)

\begin{tabular}{|c|c|c|c|c|}
\hline & April & May & June & July \\
\hline \multicolumn{5}{|l|}{1965} \\
\hline \multicolumn{5}{|l|}{ Temperature ${ }^{\circ} \mathrm{C}$} \\
\hline Daylight (max.) & $15-31 \quad(22)$ & $20-30(25)$ & $23-35(29)$ & $25-36(30)$ \\
\hline Night (min.) & $-5-9 \quad(2)$ & $-4-13(4)$ & $2-12(7)$ & $10-16(13)$ \\
\hline \multicolumn{5}{|l|}{ Precipitation (inches) } \\
\hline Maximum (24 hours) & 0.18 & 0.03 & 0.27 & 1.05 \\
\hline Monthly total & 0.34 & 0.04 & 0.83 & 4.47 \\
\hline \multicolumn{5}{|l|}{1966} \\
\hline \multicolumn{5}{|l|}{ Temperature ${ }^{\circ} \mathrm{C}$} \\
\hline Daylight (max.) & $18-26(22)$ & $22-31 \quad(27)$ & $25-35(30)$ & $24-36(31)$ \\
\hline Night (min.) & $-5-6 \quad(0)$ & $1-9 \quad(5)$ & $3-14 \quad(8)$ & $11-16(13)$ \\
\hline \multicolumn{5}{|l|}{ Precipitation (inches) } \\
\hline Maximum (24 hours) & 0.53 & 0.05 & $1.45^{*}$ & 1.06 \\
\hline Monthly total & 0.53 & 0.11 & 1.67 & 3.77 \\
\hline
\end{tabular}

* Fell on 30 June.

Grass and other low vegetation was sparse in portions of the canyon where cattle grazed. Elf Owls appeared to be little affected by cattle.

Observations were made each year in Guadalupe Canyon (Fig. 5), along the Arizona-Mexican border. The predominant trees were sycamores and huge cottonwoods, with oaks bordering the canyon walls, and mesquite (Prosopis) growing in the broad lower end of the canyon and on the desert adjacent to it. Guadalupe Canyon is hotter and drier than Cave Creek Canyon.

Elf Owls were located and observed also for short periods of time in several Mexican states, in the Rio Balsas Basin. In April, 1966, breeding birds were located near Rijo, Puebla (Fig. 3 lower), and in Benson State Park, in extreme southern Texas. 

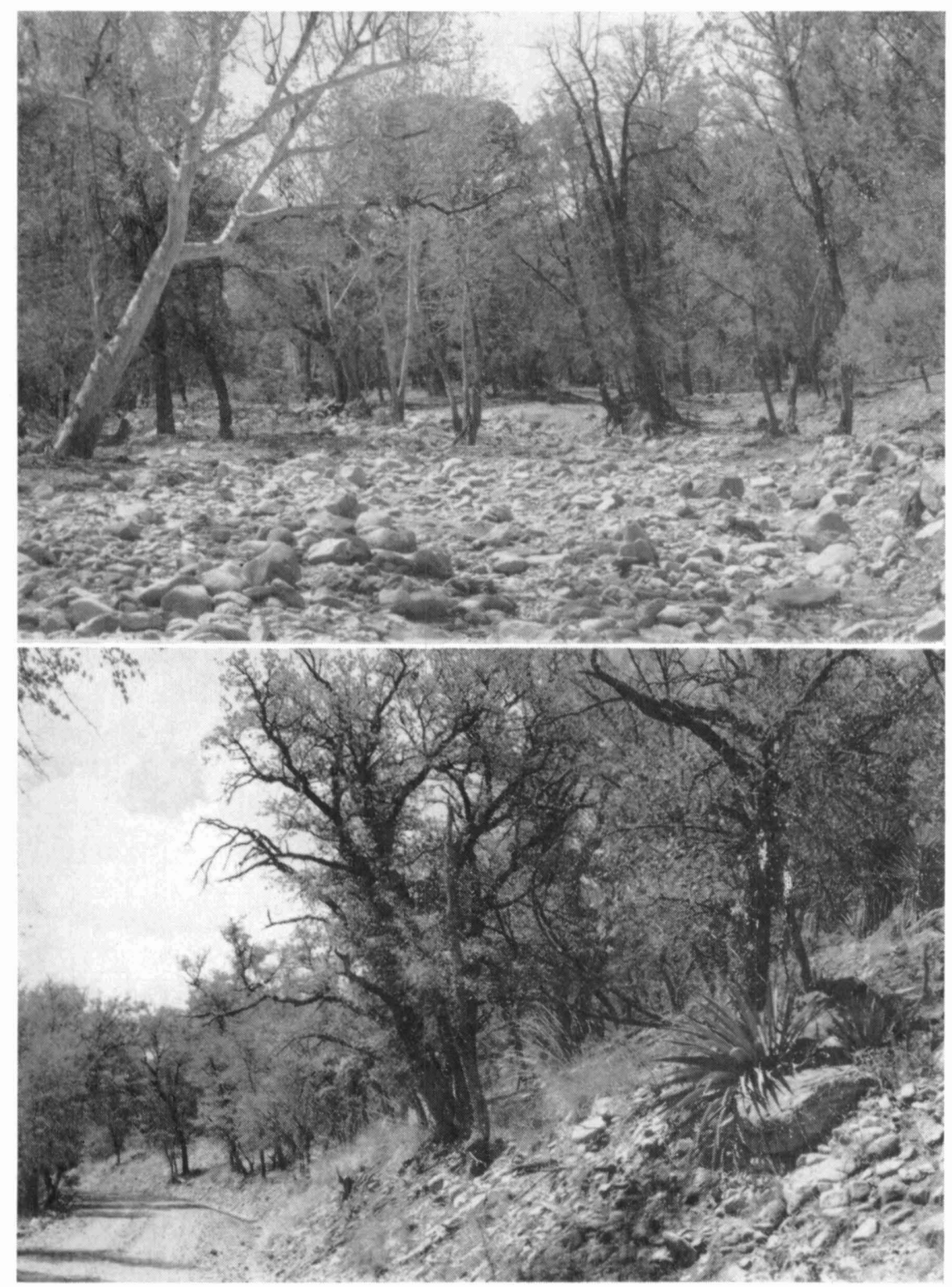

Fig. 4 UPPER. Cave Creek, Chiricahua Mountains, Arizona, along which Elf Owls nested. of Elf Owls.

LOWER. Oak-covered hillside in Cave Creck Canyon, a favorite foraging site 


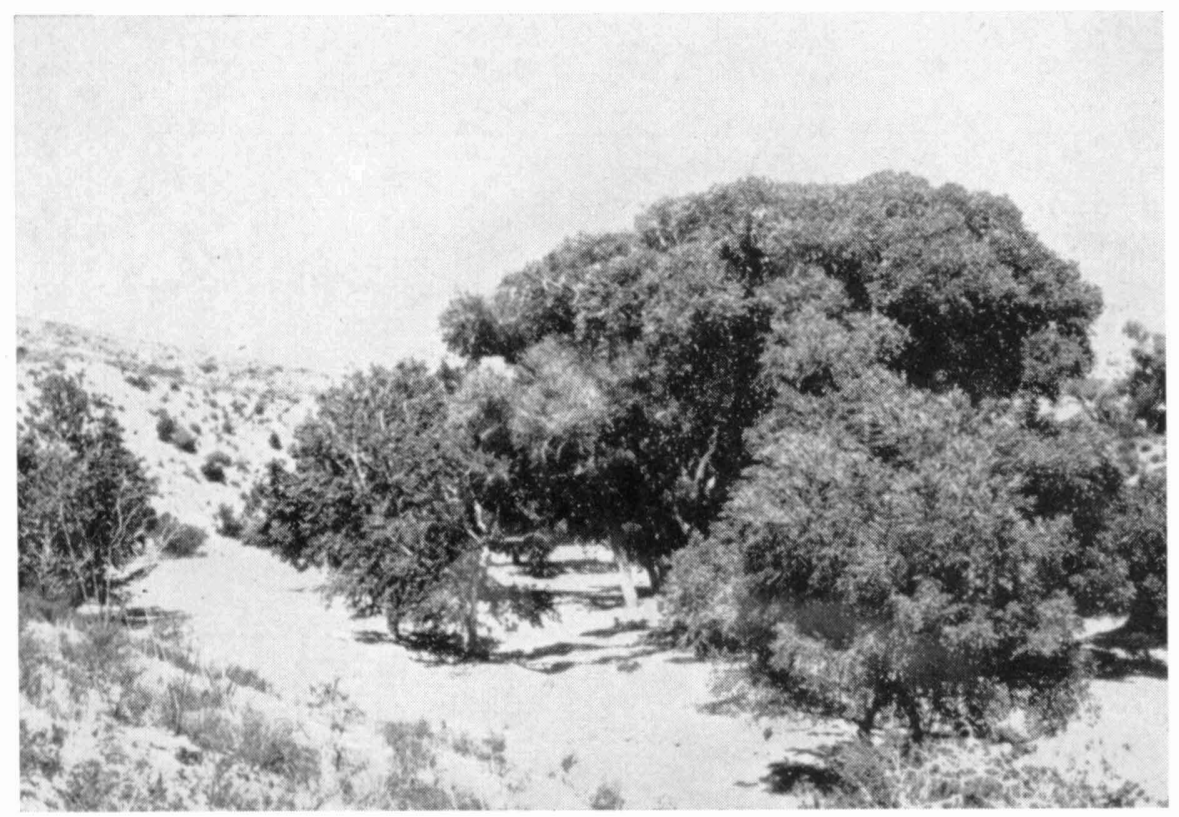

Fig. 5. Guadalupe Canyon, Arizona

VOCALIZATIONS

The vocal repertoire of the Elf Owl includes about a dozen different calls, most of which were recorded with the use of a Uher 4000 Report-S Tape Recorder.

Sonagrams of the two types of song of the males were made. Other calls are presented phonetically below, with a brief statement of their meaning and the context in which they were given.

Fortunately, certain calls are given by only one sex, making it possible to keep track of each member of the pair. This method of sexing the living birds was verified by collecting, and also by noting which bird passed the day in the nest hole. L. Miller (1946) also mentioned the diagnostic call of the female.

SonGs.-The songs described here were given only by males. Figure 6 illustrates two songs which I have designated as A and B. Song A was recorded from three localities in Arizona, from southern Texas, from Puebla, and from captive birds in the laboratory. This song varies in length, consisting of 5 to 15 or more notes, and may be repeated for long periods of time. It serves in territorial proclamation and defense as well as to advertise the presence of the male to females.

Song $\mathrm{A}$ is subject to great variation within an individual. It is influenced 


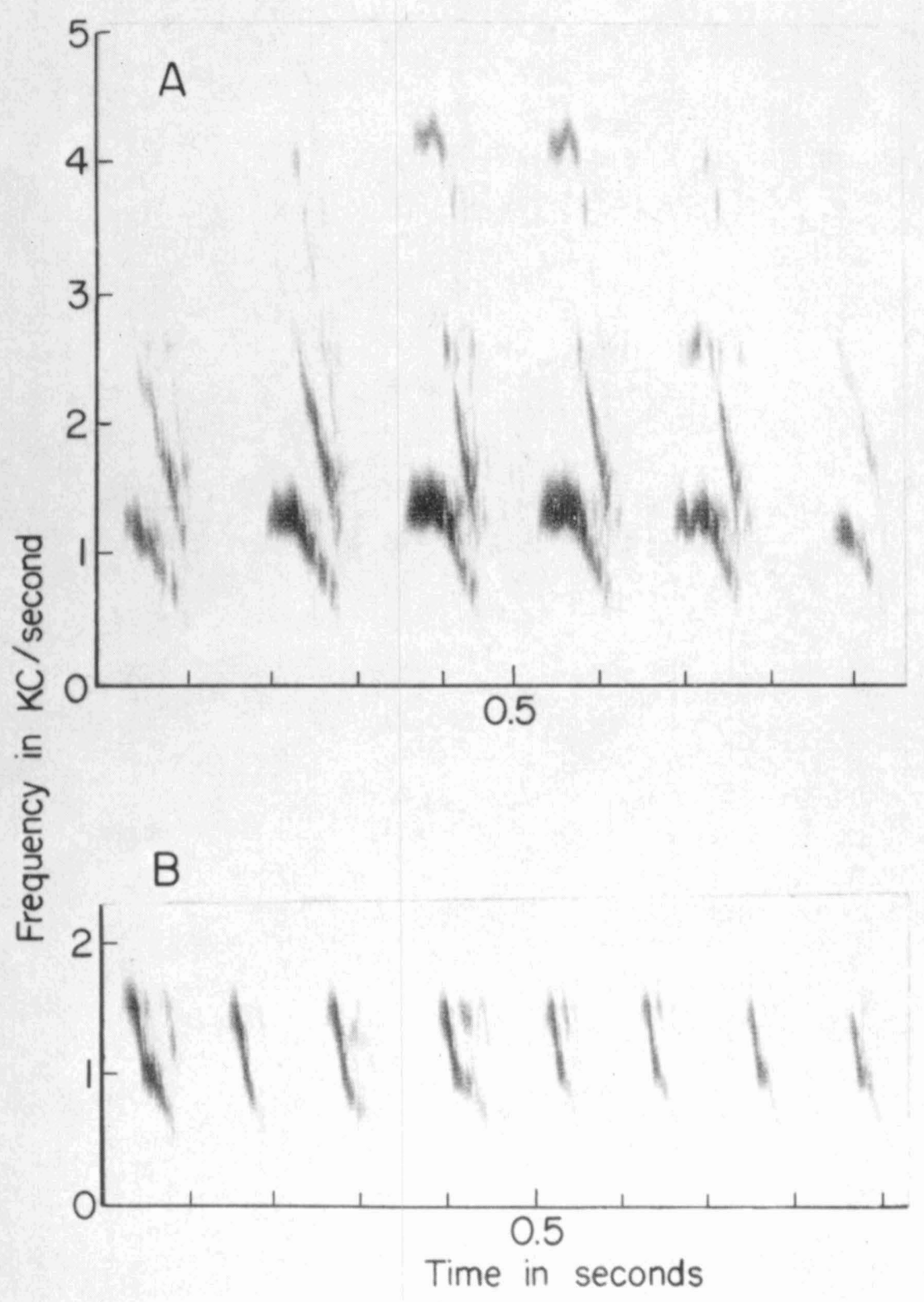

FIG. 6. Sonagrams of two songs of male Elf Owls. A, advertising song; complete song shown here. B, song given in the cavity, serves to stimulate the female; only a portion shown. 
by season, temperature, wind, and especially by conditions of moonlight. I noticed repeatedly a strong correlation between visibility and brightness of the moon and song. This was striking on 8 June, when clouds moved across the sky and intermittently obscured the moon. When the moon appeared Elf Owls started singing. Song ceased almost immediately when it was covered. Marshall $(1957: 41,78)$ also refers to the correlation between conditions of moonlight and Elf Owl song. Often a male would sing near or at the research station, probably stimulated by the artificial lighting, whereas away from the station no owls would be singing. However, song was heard occasionally on moonless nights.

As the season progresses, Song A is heard less frequently, although birds at one area sang vigorously on 30 July.

Song B functions to stimulate the females to accept and enter the cavities located by their mates. It is illustrated in part in Figure 6 . It is sometimes continued for minutes on end, with little or no noticeable pause between series of notes. It varies in volume and intensity, increasing in both as the female responds more strongly to it. When she approaches the entrance, the male usually descends slowly into the cavity, decreasing the volume of the song until it is barely audible at ground level.

Locational Call of the Female.-This will be designated as Call C in future discussion. L. Miller (1946) terms this note the "station call" of the female. It is a single "peeu" or "seeu," repeated throughout much of the night, both before and after the beginning of incubation. It assists the male in locating the female.

Flight Song of The Male.-This short song is sometimes given by the male as he flies from a cavity that he had been demonstrating to his mate. It gives the impression of excitement, as rate and volume increase from one series of notes to another. I phoneticize it as CHUR-ur-ur-ur, CHUR-ur-ur-ur.

SCOLD.-This may be given by either sex and usually indicates that the bird is disturbed. It is often heard at dusk as the adults come from their day roosts. It usually consists of a single sharp "cheeur" or "wheeur," and may or may not be repeated in rapid order. The puppy-like yippings mentioned by many authors are probably of this type. The tail is often flipped rapidly from side to side as the owl scolds.

Pre-copulatory Call of the Male.-As the male flies towards his mate prior to copulation, he gives an excited "che-o che-o che-o" call. Similar calls may be given as he flies from the female, and on some occasions, as he flies from the nest site. It seems to be a general note of excitement.

Copulatory Note of the Female.-During copulation the female utters a shrill "sheee ..." call. It ceases the moment the two birds part. 
Food Call of the Female.-Some females regularly gave a distinctive call when fed by their mates, while others did not. The note is a drawn out "rrrrrr...." This is probably the "cricket-like trill" mentioned by L. Miller (1946).

Food Calls of The Young.-A rasping call is given repetitiously by the young, at a rate and volume that appear to depend on their state of hunger. Puzzlingly, on some nights this call was not heard. As the young receive food, a high pitched trill is given. Walker (MS) describes the ventriloquial character of this call.

In addition to these easily categorized and described calls, duets were occasionally given by the pair. The female's notes were most like song A of the male, but softer and of shorter duration. Marshall's description (in Pough, 1957), "yips, whines, and barks like those of a young puppy," characterizes these duets.

A female, apparently attempting to call her young from the nest during daylight hours, gave regularly spaced soft notes that sounded to me like mellow scolding notes.

\section{ARRIVAL ON THE BREEDING GROUNDS}

Elf Owls have been recorded in Arizona as early as late February (Phillips et al., 1964:53), but they do not arrive in numbers before mid-March. In the collection of A. R. Phillips are five specimens from Arizona taken prior to $16 \mathrm{March}$; all are males. My limited observations in Arizona in early April also indicate that the first returning birds are males.

On 2 April 1966 I stimulated a male to sing a weak song (A) at the base of Cave Creek Canyon by imitating the location call $(C)$ of the female. Neither this bird nor any others were found in this canyon on the following night. However, on 4 April in the lower, more southern, and much warmer Guadalupe Canyon, several males sang fervently. One was mated, while the others appeared not to be. I returned to Guadalupe Canyon on 12 April and found that 6 of 7 males located on the previous visit were mated and had chosen nest cavities. On 13 April, I searched Cave Creek Canyon again and located a single, softly singing male. In Benson State Park, Texas, on 15 April, many Elf Owls were heard and at least one female was incubating.

Thus, it appears that males precede females in returning north, and that the more southern populations and those of lower altitudes breed somewhat earlier than do birds that nest in mountain canyons. My impression is that the first males to return to southeastern Arizona establish territories at the lower altitudes, and that additional males move up the canyons as suitable habitat is filled at the lower levels. This is suggested by the presence of some apparently non-breeding birds in the pine-oak woodland, 
although Elf Owls do breed in this habitat. Marshall (1939) stated that Flammulated Owls (Otus flammeolus) arrive later in spring, and consequently probably breed later at higher altitudes than they do at the lower zones.

\section{PAIR FORMATION}

My field work in Cave Creek Canyon in 1965 began in May, after the Elf Owls were mated. Consequently, my observations on pair formation are limited to one night, 4 April 1966, in Guadalupe Canyon. On this night the moon was full and several males sang almost continuously. Two sang (A) about 50 yards apart, while a third bird, which subsequently proved to be a female, was observed foraging quietly in mesquites about equidistant from the two males; the three birds formed the points of a triangle. The female gave several scold-like calls that seemed to cause an increase in the intensity of the songs of the two males. Shortly thereafter, she flew to a tree directly between them and called several times. One of the males then flew to a tree near her, continued to sing, and she began for the first time the typical call (C) of mated female Elf Owls. This male flew away shortly and resumed singing with great fervor from his original post. The other male also continued to sing, but did not approach the female. Several minutes later, the first male returned to the female, who had moved into a low bush where she continued to call $(\mathrm{C})$. He left her and flew downstream, where he began another song $(B)$ from a cavity. He then stopped singing, but began again when the female flew towards him. She gave scolding calls and the male flew from the cavity, giving the flight song. A short time later he re-entered the cavity, emerged, and flew to a second cavity; while in each he sang. The female remained near by, and her calls indicated a willingness to be fed by him. Formation of the pair bond is probably completed when the male begins bringing food to the female.

Of seven singing males located on 4 April, only one had a mate. Loud persistent song (A) appears to be important both in attracting a mate and in advertising to neighboring males. In the observations described above, the male that the female followed appeared to be the louder, more aggressive bird of the two in her vicinity.

\section{PAIR RELATIONS}

Elf Owls in Arizona typically are mated for a period of at least three months. In this section I describe chronologically the behavior of mated pairs from soon after pair formation until the young fledge. In order to avoid repetition, calls and songs most commonly used are referred to by letter, as described earlier.

Following pair formation, the male and female usually remain near one 
another with the prospective nest tree the focal point of their activities. Contact is facilitated by the locational call of the female (Call C), repeated monotonously throughout most of the night. She is fed regularly by the male, although at this stage she also forages independently. Periods during which the male sings alternate with periods of foraging and of feeding the female.

Nest Site Selection.-The male appears to have one or more potential nest sites located prior to the arrival of the female. After obtaining a mate, he sings from his cavity or cavities. Observations on a male with two cavities in Cave Creek Canyon follow: On 13 May he sang (Song A) from perches very near cavities located in sycamore trees 55 feet apart, flying from one tree to the other with little time between sessions of song in each. Copulation took place in the tree later selected; the two birds then flew in opposite directions. The male soon returned to this tree and resumed singing. He then flew, singing in flight. About a minute later the female returned and resumed calling (Call C) for 10 minutes. I then left this pair. On 17 May, the male sang from inside the cavity later used (I did not see him enter either cavity earlier). From this date on, all activity centered around this cavity.

SingING FROM THE CAvity.-Females respond positively to the calls of their mates by coming to them, and into cavities. As a female approaches her mate, who is singing from inside the cavity with his face at the entrance, his song changes from Song A to B, increasing in volume, duration, and rate. One male sang continuously from his cavity for 32 minutes, only one of several long sessions he engaged in that night. As the female approaches or attempts to enter the hole, the male slowly withdraws into it, decreasing the volume of his song. A typical sequence of events culminating in the entrance into the cavity by the female is described below.

On 14 May a male began singing near his prospective nest site at 8:15 P.M., after the moon had risen. At 8:20 he entered the hole and continued to sing (Song A). At 8:24, while he sang, the female flew to the hole and perched at its entrance. The male then disappeared inside the cavity and changed to Song B. The female started to enter, then abruptly flew away. The male continued to sing (Song B) without returning to the entrance, and at 8:26 the female returned to the hole and hovered in front of it for a moment before leaving again. She returned at 8:28 and entered the cavity. The male left almost immediately, followed by the female. Both birds were then silent.

The male always flies from the cavity almost immediately after the female's entrance. At first the female follows him out, but later remains in the cavity for increasingly longer periods. These activities are repeated many times throughout several consecutive nights. Brandt (1951:361-362) describes 
this activity in a pair of Elf Owls, but he apparently misidentified the sexes.

Two less typical series of observations, made of other pairs, illustrate some of the variation in this basic behavioral pattern.

1. At 8:33 P.M. on 10 May both members of a pair were in their nest tree giving "excited" calls and chatters. The male then entered the cavity and began singing, while the female called (Call C). She soon flew to the cavity, back to a nearby branch, then to the cavity where she attempted to enter without success. While the male sang, she flew back and forth in front of the entrance, obviously agitated, and finally perched on the stub containing the cavity for a short time before flying out of sight. At 8:40 the male came from the nest and the female returned to him, giving Call C. He responded with a similar, barely audible call. Both then took flight, hovering moth-like among the branches of the nest tree, with the female behind the male. The male returned to the cavity and began Song B while the female called $(\mathrm{C})$. At 8:44 he flew from the cavity. When he returned at 8:47, the female was inside calling $(\mathrm{C})$ at regular intervals. She soon came from the hole but remained in the nest tree. The male then flew to an exposed dead oak branch about 12 yards from the nest hole, before flying away. The female remained, calling $(\mathrm{C})$ softly. At 9:04 the male returned to the nest tree and was followed through the branches by the female. Copulation took place at 9:09 on a dead twig about two feet from the nest hole. The male then left, but returned within a minute and fed his mate. As the birds faced each other on a small branch, he chattered softly while she called $(\mathrm{C})$. The male then hovered above the female for a moment before departing; she became quiet and remained perched. I left this pair at 9:25 and returned at 10:10. At 10:15 the male flew to the female, fed her, nibbled at her wing, and then flew away. At 10:54 copulation again occurred, but no additional interactions were observed around the nest cavity.

2. A display observed at dusk (7:30-7:40 P.M.) on 26 May probably was triggered by the presence of other Elf Owls nearby. The male flew to and fed the female as she perched in the nest tree. At his departure, the female followed him closely, fluttering her wings rapidly as the two birds moved through the foliage (see fig. 4, in Jansson, 1964). Soon the male approached his mate and they "billed" for 30 or more seconds. The female then returned to the nest site and the male disappeared. When he returned and called, she flew towards him, landing a few inches away. The male mounted her and after copulation flew in a large semicircle, with the nest tree as the approximate center, chattering loudly throughout the flight. He then alighted in the nest tree and the female entered the cavity. The male disappeared and, after a conflict with an adjacent pair, returned. He flew high, alternately flapping and gliding, with his wings held high while gliding. 
The Gavity as a Day Roost.-In Cave Creek Canyon prior to breeding, Elf Owls of both sexes roost during the daylight hours in densely foliaged trees or bushes. Several other authors have mentioned that the Elf Owl frequents cavities only when breeding (Scott, 1886; Bent, 1938:442). The female is enticed to pass the day in the cavity in much the same manner used by the male to "encourage" her to enter it at night. By this time, however, she is familiar with it, and enters it for varying lengths of time throughout the night.

At dawn the male returns and perches near the hole where he sings and chatters. The female flies to him and the song appears to stimulate her to enter the cavity. In one pair this behavior was first observed on 14 May. The male flew from the nest site upon the female's approach, and she followed him. He returned to the cavity and resumed singing, but the female did not return, and he soon left.

A similar, but successful, effort by the male to encourage the female to enter the cavity was observed in another pair. The male flew up the oakcovered hillside when the female entered. Two days later (8 days before the first egg was laid) she went into the hole with no encouragement from the male.

The female is clearly "ill at ease" in the cavity for the first few days that she roosts in it. Even a slight noise near the nest tree will cause her to peer out, and if the tree is climbed, she readily leaves. Willard (1912) states that prior to oviposition the bird is likely to peer out at an intruder for several minutes before retreating into the hole so slowly that movement is barely perceptible. I, too, have observed this slow withdrawal into the cavity. Peering from the nest hole by the occupant, and consequent filling of the dark entrance, makes the hole less conspicuous. I have observed this behavior in woodpeckers as well as in four species of owls. The hole is much more difficult to see when there is a bird in the entrance. Norburg (1964) also suggests that a function of peering from the cavity might be to make the opening less conspicuous.

Feeding the Female.-The male feeds the female from the time the pair bond is formed until the young are one-half way through their nestling life. On 25 May, eight days before the first egg was laid, a male fed his mate nine times between 7:57 and 8:56 P.M. The female was in the cavity for eight minutes of this time, and was fed twice while she was there.

Copulation.-Copulation was observed on many occasions and there appeared to be little variation in the act or in the activities preceding it. It often occurred in the nest tree. A diagnostic call from the female was heard during all copulations observed (see Vocalizations). A typical copulation observed on $25 \mathrm{May}$ is described here. A male flew to his mate, fed 
her, and perched about two feet away. He then turned about, faced the female, and gave excited calls (see Vocalizations) before flying to and mounting her directly. She perched crosswise on a horizontal limb, giving the call mentioned above. The male fluttered his wings rapidly during the four seconds of copulation time. He then flew quietly away. After one minute the female resumed calling (Call C).

This general pattern is repeated several times in a night; the two most closely spaced copulations that I observed for one pair were 35 minutes apart. Coitus was observed only once after the eggs were laid, on 29 May. An attempt by another pair on 15 May terminated with both birds entangled in mid-air, possibly as a result of unreceptiveness on the part of the female. They dropped about three feet before separating and flying away.

In the Little Owl (Athene noctua), the female also produces a shrill shrieking sound during copulation and the male flaps his wings vigorously. Following the act, the male often flies in a semicircle and alights back at the nest hole (Haverschmidt, 1946). Copulation in the European Pigmy Owl (Glaucidium passerinum) is preceded by a mewing call from the male and a faint whistle from the female (Jansson, 1964). Copulation in the Whiskered Owl (Otus trichopsis) is similar to that of the Elf Owl, including a similar note given by the female (personal observation).

Behavior Following EgG-LAying.-Five days are required to complete a clutch of three eggs, and three days for a clutch of two. During this period the behavior of the pair is similar to that seen earlier, except that the females appear to be more reluctant to leave the nest at dusk. Males generally showed no inclination to enter the nest at this stage, but one male did enter and sing after two eggs of a three-egg clutch had been laid.

The female may leave at dusk either before or after having been fed at the cavity entrance by her mate. In many cases she flies from the cavity in response to the call of the male. In one instance the female appeared at the nest entrance and withdrew five times between 7:28 and 7:48 P.M. before flying from the hole. The following night she was up and down three times before leaving.

During incubation, females forage independently at dusk. Individuals showed a high degree of regularity in their return to the nest as darkness fell after their period of foraging. An incubating female, observed on five nights between 14 and 26 June, re-entered her nest each night between 8:04 and 8:09 P.M. Another regularly foraged for a somewhat longer period and returned to her cavity at about 8:15 P.M.

The female generally remains in the nest throughout most of the night, giving the $\mathrm{C}$ call at varying rates. One that returned to her nest by 8:05 P.M. was fed by her mate at $8: 10,8: 14$, and $8: 16$. At $8: 13$ she called $(\mathrm{C})$ at the rate 
of 28 times per minute. Another called 11 times per minute at 9:24. This call typically decreases both in rate and volume with time (as the female becomes replete). A female whose mate was disturbed by the proximity of another pair, and who consequently was not fed regularly, called more loudly than other females heard, and also was out of the nest more frequently and for longer periods than were the others. Lack (1966:141) states that the male Tawny Owl (Strix aluco) feeds the female assiduously at the nest, and desertion by her seems usually to be caused by his failure to bring enough food.

After the eggs are laid, the female Elf Owl exhibits an unusual behaviorism, first described by Brown (1903). When the nest is examined during the day, or the female is removed from it, she appears to be unconscious. I first thought the females were in some sort of torpor, but after fixing occupied cavities so that they could be opened quickly, I found that the closed eyes and comatose behavior were in response to an invader. Body temperatures of these birds were not depressed. When I checked one bird at 7:30 P.M. she was so stiff and still that I initially thought she was dead. Willard (1912) tossed such a female into the air. She dropped almost to the ground before spreading her wings and flying away.

Occasionally I examined nests at night. The females generally flew from the nest as I climbed, joining their mates in scolding me. One female, however, refused to leave, behaving as described above, although I had heard her calling less than two minutes earlier.

Behavior During the Nestling Period.-The relationship of the pair gradually changes during this period, as the female remains in the cavity progressively less, and depends less on the male for food. As discussed under "Care of Young," the female remains in the cavity with the young much of the time when they are small, and at this time both she and the nestlings are largely provided for by the male. The increasing food demands of the young may determine when and for how long the female leaves the nest and forages independently.

The female Elf Owl continues to call $(\mathrm{C})$ from the vicinity of the nest and occasionally enters it even after she has ceased remaining in the cavity at night with the young. Her calls outside the nest do not elicit any obvious response from the male. One female entered the cavity with her single wellgrown young on 20 July, well after the usual period of such behavior. Before entering she had called from near it from 7:43 to 8:10 P.M. with no reaction from the male. He brought food seven times in the next 22 minutes. She appeared to pass some of the food to the juvenile below her. A few evenings later, this female appeared to be following the male to be fed. Other females varied in the degree to which they gave Call $\mathrm{C}$ late 
in the breeding season. None appeared to be f£d by her mate at this time. After the female no longer stays in the cavity with the young, the male usually provides for the young without her assistance (see "Care of Young").

Vocalizations of the males change at this time. Prior to fledging of the young, but after the female no longer enters the cavity at night, the male (or some males) gives calls similar to, but distinguishable from, the location call of the female. Song $A$ is continued throughout the summer, but with decreasing frequency. On 30 July I recorded much singing and territorial behavior between two males with adjacent territories. For the first time in several days there was no rain, and the moon was visible.

Discussion.-The nest cavity demonstration, in which the male Elf Owl sings from the hole, is similar to that described by von Haartman (1956) for the unrelated Pied Flycatcher (Ficedula hypoleuca). Other species of strigids, notably the Little Owl, Scops Owl (Otus scops), European Pigmy Owl, Tawny Owl, and Tengmalm's Owl (Aegolius funereus) are known to have a display in which the male sings from a potential nest site (Haverschmidt, 1946; Konig, 1965). This display probably serves the same function as that of the Elf Owl. In addition to calling from the cavity, the male European Pigmy Owl deposits food in it for the female (Jansson, 1964).

The female begins roosting in the cavity from one to two weeks prior to laying the first egg. Her periodic returns to the nest throughout the night, and feedings by the male when the female is inside or outside the nest hole, appear to be steps preparing both birds for particular duties in reproduction. The male, already responsive to the food or locational calls (C) of his mate, becomes accustomed to taking food to the cavity, although he cannot see her much of the time. Her appearances outside the nest, where she is also fed, may provide visual stimulation that strengthens the feeding response of the male. This also gradually prepares the female for her dependence on her mate and for the almost constant incubation that she alone performs.

Another possible function of the early occupancy of the cavity by the female Elf Owl is to prevent other hole-nesting species from acquiring it. The presence of even a small owl in a cavity would likely discourage most small birds prospecting for a nest site. As Elf Owls nest late in Cave Creek Canyon, the first eggs being laid in the last week of May, it might be important to have a nest site well before that time. In areas where Elf Owls breed, there are several other hole-nesting species dependent on woodpeckers for nest sites. In Cave Creek Canyon there are at least eight potential competitors for nest holes, exclucling woodpeckers or other species of small owls. They are: Coppery-tailed Trogon (Trogon elegans), Sulphur-bellied 
Flycatcher (Myiodynastes luteiventris), Wied's Crested Flycatcher (Myiarchus tyrannulus), Ash-throated Flycatcher (M. cinerascens), Olivaceous Flycatcher (M. tuberculifer), Bridled Titmouse (Parus wollweberi), White-breasted Nutchatch (Sitta carolinensis), and Eastern Bluebird (Sialia sialis). The last-named species is a recent addition to the breeding avifauna of Cave Creek Canyon, having become relatively common near the research station since 1960 (see Phillips et al., 1964:131).

\section{NEST SITES AND NEST}

Elf Owls appear to be completely dependent on woodpeckers for nest sites. In Cave Creek Canyon, the Acorn (Melanerpes formicivorus) and Arizona (Dendrocopos arizonae) woodpeckers provide most of the cavities. In Guadalupe Canyon, most cavities used by the owls were excavated by the abundant Gila Woodpecker (Centurus uropygialis). This species and the Gilded Flicker (Colaptes chrysoides) appear to be the primary excavators in saguaro cacti (Carnegiea gigantea) in the desert near Tucson, Arizona. In Benson State Park, Texas, the Golden-fronted Woodpecker (Centurus aurifrons) appears to provide most nest cavities. Elf Owls were found in cavities excavated by Ladder-backed Woodpeckers (Dendrocopos scalaris) in or near Big Bend National Park, Texas (Van Tyne and Sutton, 1937:38).

Details of nest sites found in Cave Creek Canyon are summarized in Table 2. Kinds of trees utilized include sycamore, pine, and walnut. Many

TABLE 2

Measurements of Nest Sites in Cave Creek Canyon

\begin{tabular}{lccc}
\hline \hline \multicolumn{1}{c}{ Measurement } & No. & Range & Mean \\
\hline Height above ground & 27 & $5.35-18.38 \mathrm{~m}$ & $10.33 \mathrm{~m}$ \\
Depth of cavity & 27 & $13.2-48.3 \mathrm{~cm}$ & $24.5 \mathrm{~cm}$ \\
$\begin{array}{l}\text { Inside diameters } \\
\begin{array}{c}\text { Vertical diameter } \\
\text { of entrance }\end{array}\end{array}$ & 26 & $7.0 \times 8.9-16.5 \times 16.5 \mathrm{~cm}$ & $10.1 \times 11.5 \mathrm{~cm}$ \\
$\begin{array}{c}\text { Horizontal diameter } \\
\text { of entrance }\end{array}$ & 27 & $3.80-7.0 \mathrm{~cm}$ & $5.0 \mathrm{~cm}$ \\
\hline
\end{tabular}

cavities in sycamores were in rotten portions of living limbs, while others were in dead limbs. The pines were dead and the two cavities in walnuts were in dead main branches of living trees. Twenty-six nests were in sycamores, four in pines, and two in walnuts. This probably reflects only the preference of the woodpeckers for excavating in the soft wood of sycamores, and the fact that sycamores often have rotten or dead limbs.

The complete histories of three cavities in Cave Creek Canyon are known. 
One was excavated in a living sycamore limb in 1964 by Arizona Woodpeckers, and woodpeckers were successfully reared in it. This cavity was not used by either woodpeckers or owls in 1965, but in 1966 Elf Owls reared young in it. A cavity excavated in 1965, also by Arizona Woodpeckers, was used by Elf Owls in 1966. A wedge was sawed from the back side of this cavity in 1965 to facilitate study of the growth of the young woodpeckers. This flaw apparently did not disturb the owls.

The only evidence, and it is indirect, for active competition with woodpeckers for a cavity follows: On 4 May 1965, an Acorn Woodpecker was excavating a cavity in a dead walnut limb. The first Elf Owl egg was laid in this hole on 1 June \pm one day. The Elf Owls thus must have gained possession of the cavity between 4 May and the final week of May.

As in other species of hole-nesting owls, there is no nest proper. The Elf Owls lay their eggs on the bare floor of the cavities. If there is either nesting material or an old nest, the eggs are deposited on top of it. However, I rarely found Elf Owls utilizing cavities with such old nests in them, and I suspect that they prefer bare cavities. The nests are usually, but not always, relatively inoffensive, as pellets and fecal material are solid. After the rains have started, however, the inside of the cavity may become moist, and its bottom extremely foul.

\section{EGG-LAYING, CLUTCH SIZE, AND INCUBATION}

EGG-LAYING.-Elf Owls typically lay their eggs on alternate days, as found by C. W. Field (in Bent, 1938:441). According to Welty (1962:289), other owls also lay their eggs on alternate days. However, the eggs were laid in one Elf Owl nest on 5, 8, and 10 June.

Elf Owl eggs are large in relation to the size of the adult; the average weight of seven partially incubated eggs in Cave Creek Canyon was 6.98 grams (range 6.4-7.5 grams). Hanna (1935) gives the mean weight of 50 Elf Owl eggs as 7.31 grams. Breeding females weight 41 to 48 grams, thus each egg produced weighs 15 to 20 per cent of the body weight of the female. Three is the most common clutch size (Table 3), so most females lay more than 50 per cent of their weight in eggs in a five-day period.

Female Elf Owls are fed extensively by the males during egg production (see "Pair Relations-Feeding the female"). This may reflect some limitation on mobility that egg production places on the female, or perhaps the cost of foraging in terms of energy expenditure during egg formation. Lack (1966:23), speculating on the significance of such feedings by males of other species, revised his earlier assumption that it served primarily in courtship, concluding that the food itself is important.

Table 4 presents information on sequence of laying, hatching, and length of incubation for five nests. 
Clutch SIzE.-Clutches of four eggs are more common in the desert than in Cave Creek Canyon, whereas clutches of two eggs are more common in the canyon than in the desert. Clutches of three are most common in both habitats (Table 3). Clutch size in the two habitats differs at the 0.05 probability level. It is difficult to conceive of a selective factor operating for smaller brood size in Elf Owls inhabiting mountain canyons. (Food is

TABLE 3

Clutch Size of the Elf Owl in Two Habitats

\begin{tabular}{lc|rrrrr}
\hline \multirow{2}{*}{ Locality } & No. clutches & \multicolumn{5}{|c}{ Eggs per clutch } \\
\cline { 3 - 7 } & & 1 & 2 & 3 & 4 & 5 \\
\hline Cave Creek Canyon & 29 & 1 & 12 & 15 & 1 & 0 \\
Dcsert near Tucson* & 61 & 0 & 8 & 36 & 15 & 2 \\
\hline
\end{tabular}

* Compiled from Bendire (1892) and Hanna (1935).

abundant; all members of the single brood of four found in Cave Creek Canyon fledged.) The wide habitat tolerance of this species, combined with the short distances between deserts and canyons in the southwestern mountains, makes it unlikely that there is enough restriction of gene flow between the populations for selection to produce different clutch sizes. I interpret the differences as being phenotypic in nature, as seen in other species of birds whose clutches are smaller when breeding begins later. Elf Owls of the canyon breed later (about two weeks) than do those of lower elevations, presumably because low temperatures may restrict food resources in the canyon in early spring. Table 1 presents temperatures in the canyon at that time.

Lack (1966:117) mentions four species of hole nesters, two migratory and two non-migratory, that breed later in cold than in warm springs, and which lay smaller clutches in years when breeding begins later. There is little evidence that food available at the time of laying influences clutch size in nidicolous species (Lack, 1966:273); thus, it appears that the inverse relationship between clutch size and date of laying is not related to food. Lack (1966:273) states that this does not seem to be adaptive, "but the fact that this occurs in four different species in the same habitat itself suggests that an adaptation of some kind must be involved."

Reduced size of clutches laid at later dates is seen both in annual variation in inception of laying and in replacement clutches laid during a single breeding season. Most species of birds, even single-brooded species, are capable of laying more eggs, if the first clutch is lost.

Reduced clutch sizes with time are not true of species with wide north- 
south ranges. In the northern hemisphere the later breeding, more northern populations frequently lay larger clutches than do those farther south. The number of broods normally fledged is another variable raised here.

InCUBATION.-Length of incubation, based on five nests, is 24 days (Table 4). The Screech Owl and European Pigmy Owl have incubation periods of 26 days (Sherman, 1911) and 28 days (Jansson, 1964), respectively.

As noted previously, incubation is performed solely by the female Elf Owl. This appears to be true also for the Screech Owl (Sherman, 1911), Little Owl (Haverschmidt, 1946), European Pigmy Owl (Bergmann and Ganso, 1965), and Saw-whet Owl, Aegolius acadicus (Santee and Grenfield, 1939).

Hatching InTerval.-Although the female Elf Owl roosts in the cavity during the day for some time even before the first egg is laid, the eggs do not hatch at regularly staggered intervals. The first two eggs usually hatch at about the same time and the third, when present, hatches about 24 hours later (Table 4). This was also seen in other nests in which the dates

TABLE 4

Dates of Laying, Hatching, AND Length of INCUBATION* IN 5 Nests

\begin{tabular}{cllc}
\hline $\begin{array}{c}\text { Clutch } \\
\text { size }\end{array}$ & \multicolumn{1}{c}{$\begin{array}{c}\text { Sequence of } \\
\text { laying }\end{array}$} & \multicolumn{1}{c}{$\begin{array}{c}\text { Scquence of } \\
\text { hatching }\end{array}$} & $\begin{array}{c}\text { Incubation } \\
\text { in days }\end{array}$ \\
\hline 3 & June $5,8,10$ & 2 on June 27, 28 & 24 \\
3 & 2 found June 3,4 & 2 on July 3, 4 & 24 \\
2 & June 2,4 & 2 on June 28 & 24 \\
2 & June $1+, 3$ & June 27 & 24 \\
1 & June 3 & June 27 & 24 \\
\hline
\end{tabular}

* Time elapsed from laying of last egg until its hatching.

† First egg broken.

of laying were not known. Incubation appears to be delayed until the laying of the second egg. Sherman (1911) found that the first two eggs of the Screech Owl also hatched at the same time, with the third and fourth eggs hatching one and two days later, respectively.

Incubation of the first egg may be delayed as described by Haftorn (1966) for several species of hole nesters of the genus Parus. He found that during the egg-laying period, when the temperature of the first egg reached a certain maximum level, the female rose and passed the rest of the night standing in the nest cavity. I opened an Elf Owl cavity at the level of its base. It contained one egg and the female was standing. Had I approached 
her from above, she almost certainly would have been flattened against the floor of the cavity. Her posture might suggest a delay in the start of incubation similar to that of the tits.

\section{CARE OF THE YOUNG}

Attendance by the Female.-After the young hatch, the female continues to pass much of the night in the nest, although early in the evening she may frequently leave and re-enter. A female with young five days old entered and left the nest three times between 7:52 and 8:06 P.M. While in the cavity, she received food from the male five times between 7:56 and 8:20. Another female, with young four days old, received food four times between 11:00 and 11:30 P.M.

The time spent in the nest at night by the female decreases after the first few nights. I last recorded a female entering her nest and calling (G) when the young were 19 days old. She remained there for three minutes. Juveniles of this age are covered by feathers and can receive food at the cavity entrance.

The female passes the day in the cavity until the brood is 17 to 21 days of age. My regular disturbance of these adults may have caused them to roost elsewhere sooner than they would have otherwise.

Feeding the Young.-The male does most of the feeding of the young. I have recorded only three certain instances of females doing so. In some other cases the female may have taken food to her brood, but this was uncertain. Evidence that the male alone, or essentially alone, cares for the young is of three types: (1) At one nest a marked female conducted none of the 36 feedings, observed in consecutive groups of 9, 9, and 18. (2) The most common evidence is the repetitious calling $(\mathrm{C})$ of the female near the nest site while the young are being fed repeatedly. This evidence is not conclusive in itself, but when viewed in the light of the following it becomes more convincing. (3) Rates of feeding were recorded automatically throughout the night for one week, as described below. On the eighth night, after the normal feeding pattern had been established, the bird (male) feeding the young was removed. The young were not fed again either on that or the following night.

Feeding of the young primarily by the male appears common in small owls. Santee and Grenfield (1939) observed the nest of a Saw-whet Owl throughout the night, and only the male parent seemed to feed the young. However, in Tengmalm's Owl, both parents feed the young (Norburg, 1964). This is also true of the Little Owl (Haverschmidt, 1946). The male was the provider at a Screech Owl nest observed by Sherman (1911), but both parents fed fledged young of that species, according to Allen (1924). 
In the Pigmy Owl (Glaucidium gnoma), the male alone brings food to the young (C. W. Mitchell, in Bent, 1938:414). This is also true of the European Pigmy Owl (Jansson, 1964; Bergmann and Ganso, 1965). In the pigmy owls, females often receive prey from the males and in turn feed it to the young.

Feeding Patterns and Rates.-Rates of feeding two nestlings were recorded automatically throughout the night for a one-week period in July 1966 by using a microswitch apparatus at the cavity entrance, joined to a battery-driven Rustrak Event Recorder. This apparatus was also used in 1965 , but I was unable to obtain reliable data for extended periods of time.

The results obtained in 1966 are shown in Figure 7. Foraging by the adults did not begin until 7:40-7:50 P.M. and terminated at about 5:00 A.M.; thus, rates of feeding over short periods at dawn and dusk were actually somewhat higher than indicated by the figure. The young were fed a total of 569 times during the week.

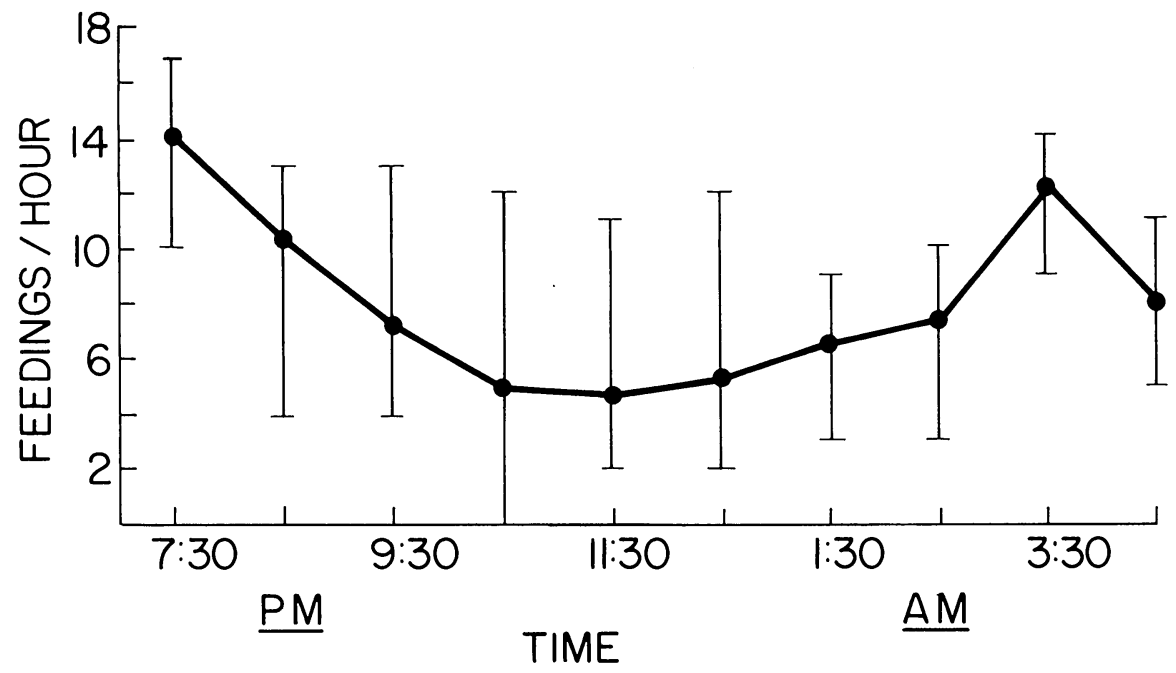

Fig. 7. Rates of feeding a brood of two nestling Elf Owls. Number of feedings were recorded automatically for the one-week period of 8-15 July 1966. Circles indicate the means of seven nights at each time period. Vertical lines show range during each time period throughout the weck.

The male is capable of capturing prey and returning to the nest so rapidly that it is difficult to believe that the feeding of the young is being done by a single bird. Three observations of especially rapid feeding rates were recorded over 5- to 12-minute periods at dusk, and ranged from 0.75 to 1.20 feedings per minute. These feedings were observed rather than recorded automatically. 
Food Calls of The Young.-Elf Owl young call repeatedly from the nest, beginning at dusk. The calls sometimes appear to be triggered by calls of the adults. Calling varied greatly from night to night, and from nest to nest. On cloudy or rainy nights juveniles were usually quiet, although they were not being fed often. Larger broods called for longer periods than did smaller broods, suggesting that hunger influences calling. The young are frequently quiet by 10:00 P.M., calling only when a parent arrives with food.

At one nest with two young 18 days old, calling rates at 9:12 P.M. were 48 per minute. The rasping call changes to a shrill note when the young bird receives food.

Muir (1954) found that the calls of young Tawny Owls were maximal at about the main feeding time, near midnight, and probably served as a guide to the parents. Calls of fledged Elf Owls probably also serve to guide the parents, as they continue to give their distinctive call after fledging.

In Tawny Owls, sight of the parent rather than darkness probably triggers the start of calling. Young normally made 12 to 15 calls per minute, and as they called more rapidly and excitedly, the calls changed in quality. Both rate and volume decreased as the young became satiated (Muir, 1954).

Food Storage.-Not all food brought to the nest during the night is consumed immediately. I occasionally found prey items in nest cavities during the day; twice these were alive but incapacitated. A large sphinx moth with all six legs and one forewing removed was found alive at midday in a nest containing young owls. At another nest, two of three crickets were alive, each with the thorax bitten so that coordinated movement was impossible. Whether the adults instinctively incapacitate prey items is unknown. However, such prey is available to the young during the 14- to 15-hour period of daylight, and is fresh rather than dried and hardened.

True food storage is known in Tengmalm's Owl and the European Pigmy Owl, both of which prey almost exclusively on vertebrates (Jansson, 1964; Norberg, 1964).

Nest Defense.-As I examined a juvenal owl at night at a nest entrance, an adult struck my hand. On other occasions, as I climbed to nests at night one or both adults would fly very close to me, scolding vigorously.

FLEDGing.-Observations of particular interest were made on 27 July 1965. At a nest at which the automatic event recorder was present, the switch had been triggered repeatedly throughout the morning. Two young of fledging age (30 days) were in the nest and appeared to be in good condition when I took them from the cavity for weighing at 11:25 A.M. I soon heard an adult giving a soft, single-noted call that I had not heard 
before. The calling bird (the banded female parınt) was in an alligator juniper about 25 yards from the nest. Her calls appeared to explain the attempts of the young to leave the nest during the day, for when I released one of them it flew directly to the parent and parched quietly. At 12:45 P.M. the adult female was still in the juniper, but was now quiet. I flushed her from the tree and she soon resumed calling from a nearby oak. By 1:35 she had returned to the juniper, where both young were now tethered, and was calling. She was again flushed from the juniper and flew to an exposed position in an oak, where she remained until 6:30 P.M. This is my only observation of diurnal activity of Elf Owls.

It is probable that the young would have left the nest on the preceding night, but the wire trigger at the entrance prevented them from doing so. One or both adults may typically call the young from the nest. The failure of these juveniles to leave the nest, and perhaps their calls as they attempted to do so, may have caused the female to continue calling through the following day. I have not observed normal nest departure by the young.

The period of post-fledging dependency is unknown. Young of fledging age fly well, and birds taken from nests and brought into the laboratory were capable of flying from perches and effectively captured crickets almost immediately.

Recently fledged Elf Owls emit the same food calls given in the nest.

\section{GROWTH AND DEVELOPMENT OF YOUNG}

The nestling life of Elf Owls ranges from 28 to 33 days. Mean weights for young in nine nests are presented in Figure 8. In some nests, the third hatched owl fared poorly, whereas in others it seemed to be at no disadvantage. Development of young is outlined below.

Hatching to two Days.-Covered with thick, immaculate white down. Apteria present dorsally and ventrally, and along the upper thigh and the sides of the neck. Skin pink; heel pads bare; feet large in relation to body, and downy to the bases of the claws. Orbital area blue; beak horn gray with cere light, especially around the nostrils. Tarsus, $1 \mathrm{~cm}$; wing from elbow about $2 \mathrm{~cm}$.

Three to Four Days.-Length of extended wing about $3 \mathrm{~cm}$; tarsus, $1.1-1.3 \mathrm{~cm}$. Feather tracts visible as darkened ridges under the skin on the wings and scapular region. Heel pads enlarged.

Five to Six Days.-Eyes open, pale grayish yellow. Wing from elbow about $3 \mathrm{~cm}$; tarsus about $1.9 \mathrm{~cm}$. Feather tracts on scapulars, wings, middle of crown, axillar region; femoral and crural tracts visible as rough darkened 
ridges under the skin; dorsal apteria more conspicuous. Commissural point is soft and yellow.

Seven to Eight Days.-Oil gland distinct. Feather tracts well marked, with short quills on scapulars, axillar, dorsal, and femoral tracts; smaller whitish quills on flanks. Feet and wings developing rapidly. Beak tip whitish, remainder gray.

Nine to Ten Days.-Able to see, to some extent; some young were alert and able to sit up; one snapped beak slightly. Feather tips out of sheaths on breast and scapulars; tarsi and feet still down-covered.

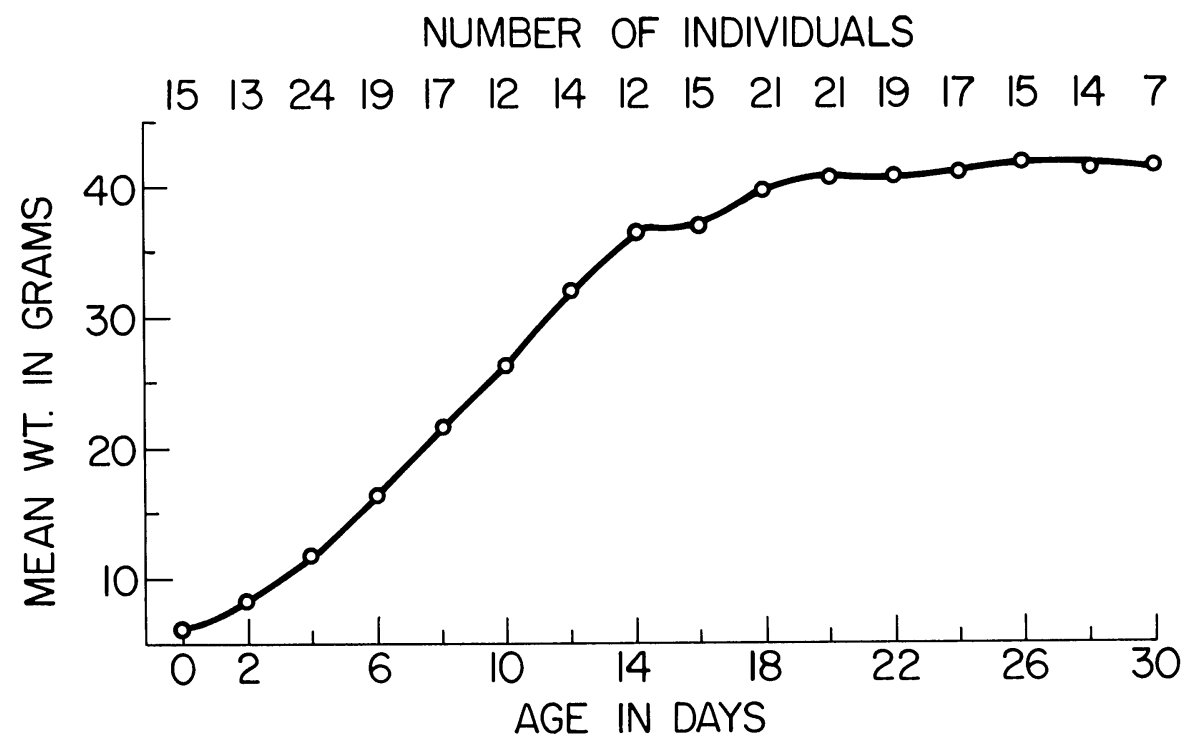

FIG. 8. Growth of young Elf Owls

Eleven to 12 Days.-One snapped beak and showed defensive behavior by rearing back on its heels and erecting quills of the breast. Back of head, and to a lesser degree crown, covered with long quills, as is upper neck and back; tips of secondary coverts erupted from sheath; feathers of axillar region free of sheaths, cover sides of breast; quills of either the rectrices or crissum visible. Commissural point still soft and yellow. Legs and feet beginning to lose down.

Thirteen to 14 Days.-Quills of remiges and greater secondary coverts long, with only tips erupted; tarsi and feet rapidly losing downy covering. 
Seventeen to 18 Days.-Birds covered by contour feathers; tails short, but visible; upper wing coverts, especially secondary coverts, more exposed than remiges; feet almost bare of down and naked, as in adults; much down attached to head, gone from most other areas.

Twenty-one to 22 Days.-Young active, for the first time attempt to fly. Under tail coverts as long as tail, which is ca. $1.7 \mathrm{~cm}$ and sheathed except for terminal $0.5 \mathrm{~cm}$; longest primary, $3.8 \mathrm{~cm}, 2.1 \mathrm{~cm}$ ensheathed.

Twenty-five to 26 Days.-Unable to fly effectively; remiges and rectrices still in quills.

Twenty-seven to 28 Days.-Of fledging age, capable of flight.

\section{NESTING SUCCESS}

Success of nesting in the Elf Owls that I studied was very high (Table 5). Nice (1957) found that success in several species of hole nesters ranged from 26 to 94 per cent, with an average of 66 per cent. In open nesters, on the

TABLE 5

SuCGess OF ELF OWL NeSTS

\begin{tabular}{ccccc}
\hline \hline $\begin{array}{c}\text { Clutch } \\
\text { size }\end{array}$ & $\begin{array}{c}\text { Number } \\
\text { clutches }\end{array}$ & $\begin{array}{c}\text { Nests } \\
\text { destroyed } \\
\text { by me }\end{array}$ & $\begin{array}{c}\text { Young } \\
\text { hatched }\end{array}$ & $\begin{array}{c}\text { Young } \\
\text { fledged }\end{array}$ \\
\hline 1 & 1 & 0 & 1 & 1 \\
2 & 12 & 2 & 181 & 18 \\
3 & 15 & 4 & $32^{2}$ & 293 \\
4 & 1 & 0 & 4 & 4 \\
\hline
\end{tabular}

1 One egg infertile, one broken.

2 One egg broken.

3 One young accidentally killed. The third bird hatched in two nests starved.

other hand, success ranged from 22 to 70 per cent, with an average of 46 per cent. The number of days of exposure (incubation plus nesting life) of hole nesters (all passerines) averaged 38; in North American open nesters it averaged 27 days. In the Elf Owl the number of days of exposure ranged from 52 to 57 . My interference with the cavities was the only cause of nest failure among those I studied.

Nice (1957) states that in addition to this advantage of hole-nesting, the young of hole nesters can fly better at fledging (presumably because they are older), thus mortality in the first few days after fledging is lower. As both Nice and von Haartman (1957) point out, the major disadvantage of hole nesting is an insufficient number of suitable nest sites. 


\section{ECOLOGY}

FORAGING BEHAVIOR AND FOOD

Foraging BEHAvior.-Elf Owls feed almost entirely on arthropods, which are captured in a variety of ways. Marshall (1957:78) describes hunting techniques observed by him.

Foraging by flying over open ground is common in areas where ground vegetation is sparse. In Guadalupe Canyon I observed a male hovering less than a foot above the ground with his wings beating very rapidly, apparently examining a potential prey item. Walker (1943) also mentions the hovering ability of Elf Owls. Two were captured in mist nets less than three feet above open ground in southern Mexico. On two occasions in Cave Creek Canyon, Elf Owls were first heard and then seen as they pursued prey among leaves on the ground.

I regularly saw owls fly from perches in pursuit of flying insects. A male was seen to leave a perch, catch a flying beetle with his feet, land on another limb, transfer the insect to his beak, and carry it to the female, who received the food with her beak. Another female, seen making repeated captures of insects in the air, demonstrated great maneuverability, veering sharply as she pursued her prey. Smith (1907) observed an Elf Owl catching moths by flying out after them and then returning to its original perch in the manner of a flycatcher. The owl presumably used its feet in making the captures.

The most common method of foraging in Cave Creek Canyon, after the rains had begun, consisted of fluttering and hovering among oak foliage and capturing insects as they took flight. A female flew against a clump of oak leaves, either in pursuit of an individual insect or to flush insects from the leaves. Afterwards, she flew directly back to her original perch with a prey item. Hunting insects by fluttering in foliage was also observed by Marshall (1957:78). Walker (MS) observed Elf Owls fluttering against Agave blossoms, apparently purposefully flailing insects from them.

This variety in foraging behavior is reflected by the food brought to the young. Foraging begins at dusk and continues at a slower pace throughout the night.

Walker (1943) first pointed out that the Elf Owl, unlike many other species of owls, is not a silent flier, which might not be important to a species feeding primarily on invertebrates.

Food.-Food items were sampled largely by removing insect remains from nest cavities. In early July noctuid moths and crickets were the primary items in the diet, but by mid-July scarab beetles formed most of the food brought to the young. This change in diet is correlated with the onset of 
the summer rains when great numbers of adult beetles emerge. At dusk in mid-July, after a rain, the noise of flying insects, primarily beetles, is impressive. The change in composition of insect populations in Cave Creek Canyon is described by Davis (1965:543): "The great shift in the distribution of the insect population, with a very evident and explosive emergence of adults, especially noticeable in certain families of beetles, that occurred at the end of June and the beginning of July was apparently triggered by the rains of 27 June [in 1961]." Rates of feeding the young are high, and one could conclude from that alone that food is abundant and is easily obtained.

Although insects form the major prey of Elf Owls, other animals also are taken. Scorpions are eaten by adults and are fed to the young. I noticed that the stinger had been removed from a large scorpion found in a nest. Four scorpions taken from the stomach of an Elf Owl all had the terminal abdominal segments missing. The hard stingers would have been recognizable had they been present. Walker (MS) also states that scorpions brought to the young have the abdomens either removed or badly mangled.

The only reptilian prey, a lizard, Sceloporus jarrovi, and a blind snake, Leptotyphlops dulcis, recorded for Elf Owls are from my study. The lizard was carried by an adult owl at dusk, and I attempted unsuccessfully to frighten the bird into dropping it. I retrieved the lizard several minutes after it had been deposited in the nest cavity. It was $9 \mathrm{~cm}$ long and $11 / 2 \mathrm{~cm}$ in maximum width. It apparently had been killed by repeated bites on the head. The single nestling owl had made no attempt to eat it. Another dead lizard, dried and unidentified, was found in an Elf Owl nest, possibly brought to the young and refused by them. The blind snake was discovered in late afternoon, many hours after it had been carried to the nest, and there was no evidence that it would have been eaten. That vertebrates are so rarely caught may be because most of those small enough to be captured by Elf Owls are usually under cover before the owls begin foraging. The apparent aversion of the young to reptiles also suggests that they are rarely captured.

Food items taken by Elf Owls are listed in Table 6.

\section{RELATIONS WITH OTHER SPECIES}

I saw interspecific contacts only twice; in both instances an Elf Owl was attacked by a Robin (Turdus migratorius). An Elf Owl of fledging age that I was weighing on 20 July escaped and flew some distance. A Robin pursued the owl, struck it, and knocked it from the air into a flowing stream. On 31 July, at 7:30 P.M., as an adult came from its day roost on an oak-covered hillside, it was pursued vigorously by a Robin. 
TABLE 6

Food Items Recorded for the Elf OWL

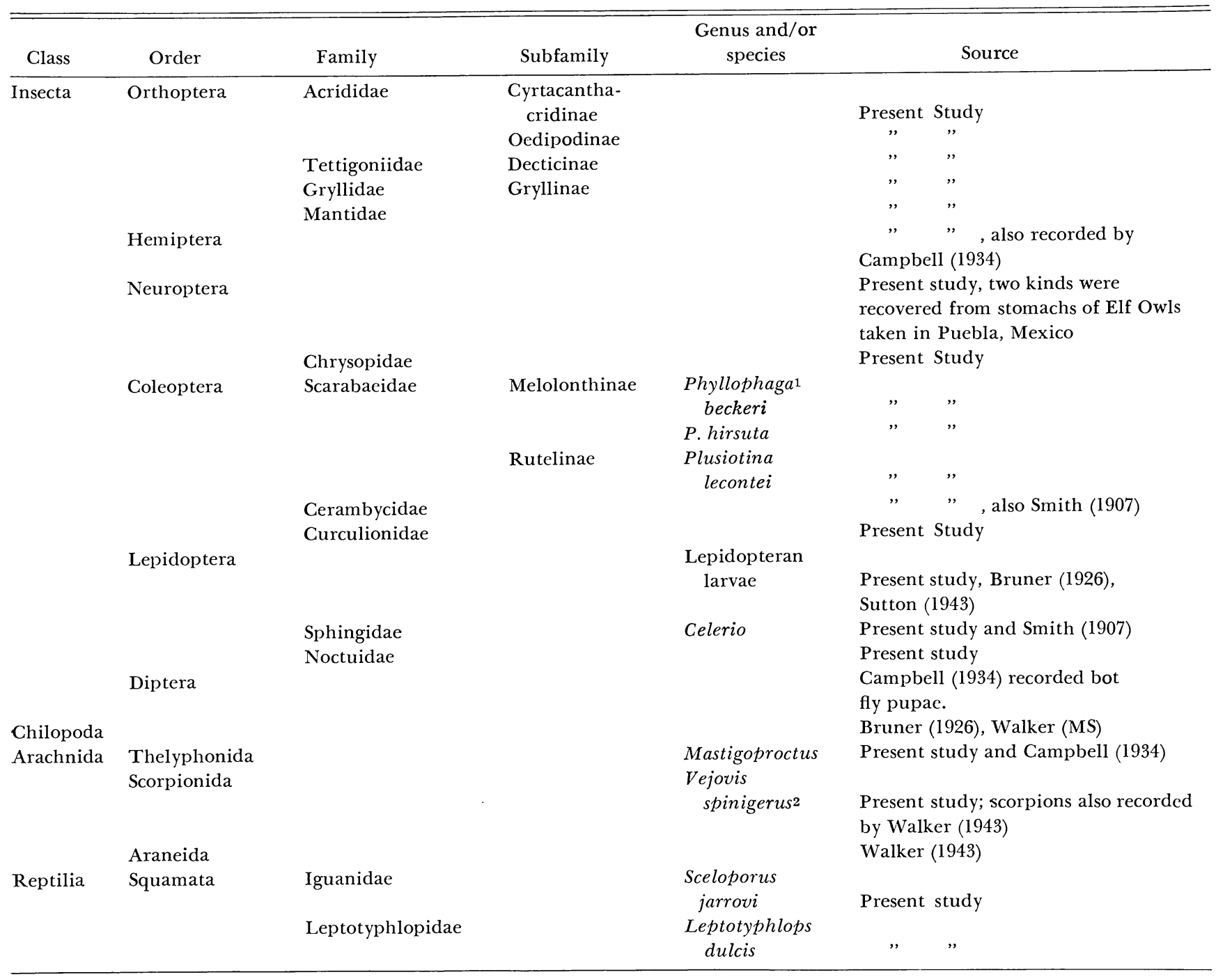


The owl flew into a large juniper and sat immobile until the Robin departed.

Nest Sitrs.-There are surely interactions between Elf Owls and other hole nesters, although I observed none. Bent (1938:440-441) provides a few examples of this: A Screech Owl was found in a saguaro cavity sitting on three Elf Owl eggs; a Gila Woodpecker was seen scolding vigorously after flying from near a cavity that contained an Elf Owl and three owl eggs; and an Elf Owl and a Wied's Crested Flycatcher exchanged nest cavities after each had been robbed of its eggs. In a cavity being excavated by Acorn Woodpeckers in Cave Creek Canyon on 5 May, I found a clutch of fresh Elf Owl eggs on 2 June. Fowler (1903) stated that he had been watching a pair of Anteating (Acorn) Woodpeckers excavate a nest cavity. $\mathrm{He}$ had the cavity opened when he judged it would have a full set of eggs only to find an Elf Owl and three owl eggs.

Marshall (1957:78) implies that Elf Owls and Acorn Woodpeckers either use the same cavities in shifts, or that they disturb each other at clusk and dawn as one species emerges from and the other retires to neighboring cavities. Two trees that contained Elf Owl nests also had cavities used by Acorn Woodpeckers. In one, the woodpeckers' roost was not more than six feet from the owl nest. Acorn Woodpeckers are noisy at dawn and dusk, as often are the owls, but I observed no interactions between the two species. Marshall (in Phillips et al., 1964:52-53) states without elaboration that Elf Owls defend their "favorite" cavities from Whiskered Owls. Many of the cavities used by Elf Owls in Cave Creek Canyon are excavated by Arizona Woodpeckers and are probably too small for Whiskered Owls.

Food.-There is almost certainly no significant competition for food between Elf Owls and other insectivorous birds. Other nocturnal, primarily insectivorous birds of Cave Creek Canyon include Screech, Whiskered, and Flammulated owls, and Whip-poor-wills (Caprimulgus vociferus) and Poorwills (Phalaenoptilus nuttallii). The Flammulated Owl, not much larger than the Elf Owl, was uncommon in the lower portion of the canyon where Elf Owls were abundant. Marshall (1957:78) observed two Flammulated and two Elf owls feeding together on insects among the flowers of large madrones. He (1957:61) states: "The Flammulated Owl and Elf Owl are of equivalent size and feeding behavior and are largely complementary in altitude, but their coexistence in maximum numbers at Cave Creek in the Chiricahuas and at Sylvania disproves competition." In the early summer of 1965 I encountered two Flammulated Owls near the research station; both apparently were unmated males. I found nests of Screech, Whiskered, and Elf owls in the lower portions of the canyon, but I 
obtained no evidenced that Flammulated Owls nested in areas occupied by the above-mentioned species. In the three years that I studied owls in Cave Creek Canyon, Flammulated Owls did not exist there in maximum numbers, judging from population densities reported from elsewhere. If Elf and Flammulated owls did exist together in "maximum numbers," there almost certainly would be competition for nest sites. As pointed out earlier, this seems to be the most common limiting factor found among hole-nesting birds. The abundance of food of the types taken by Flammulated and Elf owls makes it unlikely that there would be critical competition for this resource.

Predators.-Elf Owls apparently have few predators. Of the 31 nests that I observed, 1964 to 1966, none was lost to predators. Screech Owls were common in the canyon and did feed on birds to some extent, but the nests that I examined contained no Elf Owl remains.

A juvenal owl that I tethered to a juniper branch in order to obtain photographs of adults feeding it on the following night, was killed and removed in the late afternoon by a strong predator. Its leg was attached to the tethering cord when I returned at dusk. I suspect a Cooper's Hawk (Accipiter cooperii), a common bird in Cave Creek Canyon, was responsible.

PARAsites.-Dipterans of the Family Calliphoridae were regularly found in owl nests. The larvae attach to soft areas of the young owls, especially between or on the toes, but occasionally on the body. They feed on the blood of the host and pupate in the nest cavity.

\section{TIMING OF BREEDING}

EFfects of Temperature.-Lack's recent (1966:24) view that the timing of breeding of some temperate zone species of insectivorous birds is most influenced by the presence of a food supply sufficient for the females to form eggs (for example, in warm, early springs with more insects egg-laying starts sooner than in cold late springs) differs from his earlier view that the time of laying was an adaptation for hatching of young when food is most plentiful (Lack, 1954). Tanner (1966) found that air temperature was the only variable shown to affect the time of laying in four species of passerines. The insectivorous Elf Owl may also demonstrate a relationship between air temperature and time of laying, but the data are scanty, and the following discussion is necessarily speculative.

In 1965, in Cave Creek Canyon, the mean date of laying the first egg in 18 Elf Owl nests was 1 June; in 1966 it was 26 May for six nests. (The dates for 1966 are approximations made by weighing and noting plumage development of young in early July and comparing them with those of birds of known age; some values in 1965 were approximated from the 
time of hatching of the first young.) There is a difference of several days (significant at the 0.01 probability level) in the laying dates of the two years. This may be correlated with a drop in temperature to freezing on the nights of 26 and 27 May, 1965. In 1965, first eggs were laid within four days (31 May-3 June) in nine of 18 nests (Fig. 9). In all, in that year, clutches were begun on or after 1 June in 61 per cent of the nests for which the date of the first laid egg was known, while in 1966 all were begun before 28 May.

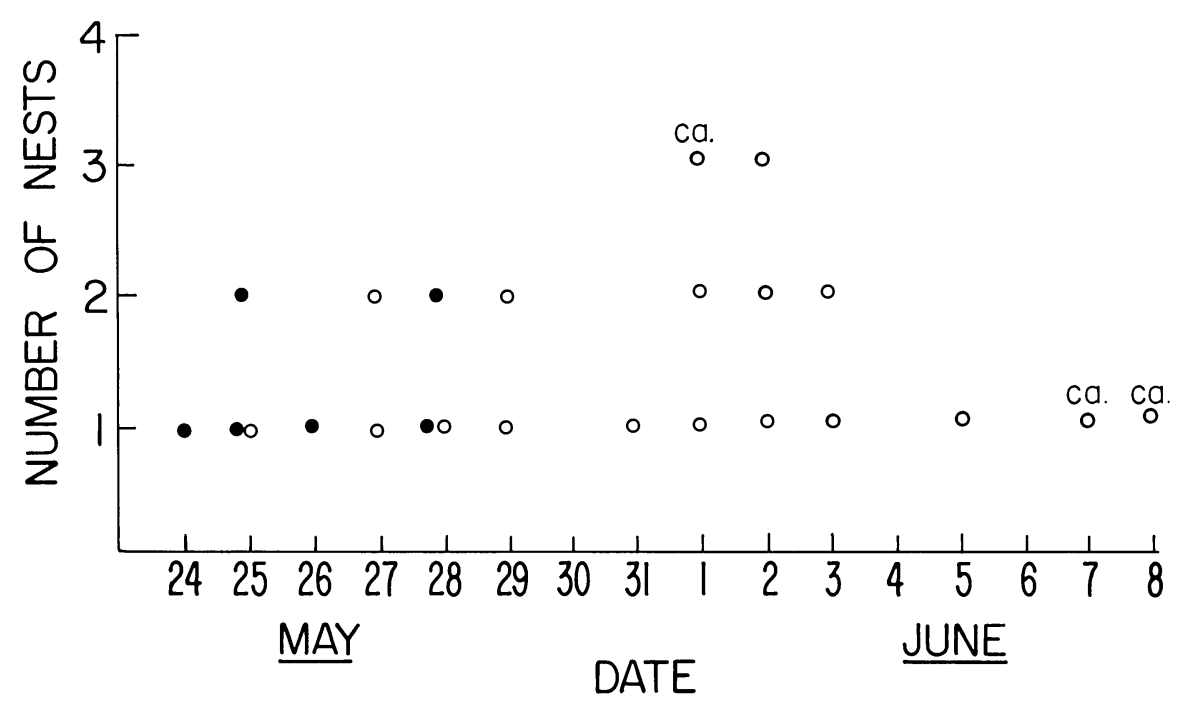

FIG. 9. Date of laying first egg in 18 nests in 1965, and in six nests in 1966. Dates for 1966 are approximations, made as described in the text, as are some dates for 1965. Open circles represent first eggs in 1965; closed circles, first eggs in 1966.

Kluijver (1951:48) found that in the Great Tit (Parus major) cold affects only the laying of the first egg, but in the Blue Tit (P. caerulescens) laying of further eggs in a clutch is often interrupted by a fall in temperature. He showed that Great Tits ceased to lay on the fourth day after the change in temperature, presumably because it is four days from the time yolk production increases rapidly until the egg is laid. A temperature drop to below freezing would temporarily decrease the food supply of the Elf Owl. It is possible that the temperature drop on 26 May delayed the start of laying in some individuals, resulting in a "burst" of laying (50 per cent) within six to eight days following the freeze.

Geographic Variation in Time of Nesting.-In Benson State Park, Texas, the breeding season had progressed further (at least one female was 
incubating) by mid-April, 1966, than at any of the sites visited in Arizona (Cave Creek Canyon, Guadalupe Canyon, Tucson). However, in Puebla, in mid-April, although the birds were paired, I saw no evidence that breeding had begun, that is, the females appeared not to be incubating, and young were not being fed.

Seasonal Rains.-In Arizona, where the Elf Owl appears to reach peak abundance, the young are in the nest and making their greatest food demands during the summer rainy season, beginning in late June or early July. Table 1 shows the monthly rainfall during the critical period for two years, demonstrating its seasonality. It is possible that in Puebla the timing of breeding is also related to the rainy season, which begins in late June (A. R. Phillips, in litt.). Dr. Phillips states that rainy season nesters probably nest, in normal years, chiefly from the end of June to August or September. However, breeding begins in southern Arizona soon after the arrival of the owls. The long incubation and nestling periods (about 55 days) necessitate an early beginning of the breeding cycle. In addition, molt appears to take place after breeding and before migration.

Number of Broons.-Elf Owls are single brooded, as are other species of strigids. The long period required for a single nesting precludes the possibility of successive broods, at least in the mountainous portions of its range. As discussed earlier, the first Elf Owls to return to Arizona in the spring apparently settle in the lower, warmer areas, and breed earlier than do those in the mountains.

\section{TERRITORIALITY}

Responses to Song.-Marshall (1957:78) states that Elf Owls do not answer imitated calls. I found that males do respond in various ways to tape-recorded playbacks of either their own song or that of another Elf Owl. An interesting response was given by two males in Puebla, where several pairs were found on 7 February 1966. The males would fly to and enter their cavities immediately upon my playing the song of an Elf Owl. One returned to a cavity in a cactus each time that I played Elf Owl Song A near it. This response was also noted in Cave Creek Canyon, but other responses were observed more commonly. Perhaps the differences in response to an intruder in the two areas is a result of the difference in availability of nest sites. In southern Mexico few sites appear to be available for nests, and the breeding population seems less dense than in Arizona, where nest sites are not so rare. In southern Mexico, selection favoring the ability to hold a suitable cavity may be very strong. This response to an intruder is like that found in the Pied Flycatcher, whose 
population size is limited by the availability of nest sites (von Haartman, 1957).

Other responses to song playback were varied. On one occasion I was attacked by a male Elf Owl that dived, from his nest tree, at my head as I held the recorder. Playback of song near the nest tree of another pair had unexpected results. The first male (1) flew back and forth over me several times (the typical reaction), then perched at his nest site and sang with great fervor before flying away. Soon three birds were at the nest site: male 1 inside the hole; his mate perched near it; and a male (2) from the next territory, who was perched at the top of the stub in which the cavity was located. Male 1 soon left the cavity and drove male 2 away. An hour later I played a recording of the song of male 2 in his (2's) territory. He flew over me several times, singing, before alighting close to me and continuing to sing. Male 1 moved into 2's territory in response to the playback, and both birds sang in proximity to each other and to me.

These responses suggest that male Elf Owls know the number of males adjacent to their territories, rather than their identities. Playback of song, as mentioned above, resulted in these two males leaving their own territories and entering that of their neighbor in response to the song of an "extra" bird. In each case the recording was of the bird in whose territory it was being played. If the intruding males recognized individual songs, they should not have become aroused and ventured into the territory of an adjacent male, whose song "belonged" in the area from which it came.

Function of Territoriality.-Some aspects of territoriality in the Elf Owl appear to be most similar to those of an unrelated hole-nesting species, the Pied Flycatcher. As emphasized by von Haartman (1957) in his discussion of hole-nesting in birds, there is often severe competition within and between species for nest sites in those species that depend entirely on cavities in trees. In the Elf Owl, as in the Pied Flycatcher and many other hole-nesting species (von Haartman, 1957), the hole itself is of primary importance both in selection of a territory and in courtship. Males probably settle on a territory only after locating a suitable cavity.

In the Elf Owl, as in many other territorial species (Hinde, 1956), mates and nest sites appear to be the objects of defense. Suitable nest sites are valuable, thus territorial behavior around the nest site protects it. The concentration at the nest cavity of courtship activities of the pair early in the breeding cycle might, in addition to demonstrating the cavity to the female and enticing her to accept it, insure that the male is present to defend it. If the male is in or near his prospective nest hole during much of the period of activity of the owls, there is little chance that it will be taken over by another male. In some species, for example the Pied 
Flycatcher, nest cavities are located very rapidly and are taken over by new individuals shortly after the owner is removed, even if only for a short time (von Haartman, 1957).

Perhaps even more important than the defense of the nest cavity, territoriality decreases interference in intra-pair interactions. The methods of communication, as well as the behavior exhibited as the pair bond becomes stronger (increased dependency of the female on the male for food, behavior of the male in encouraging the female to accept, enter, and roost in the hole) would likely be, and in a few observed instances were, interfered with by other Elf Owls were it not for the sanctuary provided by the territory.

Interactions Between Pairs.-Observations in Guadalupe Canyon in April 1966 indicated the disruptive effect that may occur when two pairs are very close together. In this case, the cavities chosen by the two pairs were only about 30 feet apart. It was possible to determine the identity of each of the four unmarked birds only when they were in or very near their respective nest sites, or when they returned to them straightaway following an encounter.

As the male (MA) of the first pair (Pair A) sang from his cavity, with his mate (FA) responding by fluttering near it, a third bird landed near the female. This was the female member $(\mathrm{FB})$ of the adjacent pair (Pair $\mathrm{B}$ ); she appeared to be responding to the fervent singing of MA. FA attacked FB, pursued her, and drove her away before returning to her nest tree. FB returned again, and was again driven away by FA. On the following evening FB again came to the nest tree of FA, attracted by the song of MA, and, as on the previous night, was driven away by FA. Earlier, MB also had come near the nest site of Pair A, and was driven away by MA, while FA was in the nest cavity calling $(\mathrm{C})$.

As both males had mates and suitable nest sites, the conflicts, I think, stemmed either from the inability of the birds, especially FB, to distinguish between the songs of $\mathrm{MB}$ and the adjacent male, MA, or her response to MA was a result of his louder, more continuous song. Further, MB may have been somewhat intimidated by the vigor of MA's song. It was apparent that Pair A had progressed further in the breeding cycle than had Pair B, as FA roosted in the cavity during the day, whereas FB did not.

In mid-July, I revisited this site, and young were heard in the nest of Pair B. None were found in the nest of Pair A or in any of five other nests located the previous April; by this date they should have fledged. Nesting was possibly delayed in Pair B by the proximity of Pair A. The following situation also illustrates the adverse effects that may occur when pairs are too closely spaced.

Two pairs that I located in Cave Creek Canyon in June, 1965, held 
adjacent territories with the nest trees only 86 feet apart (Fig. 10). Pair D was in the early stages of breeding (no eggs had been laid) at this late date, although they had been there since at least 5 June, while the female of Pair $\mathrm{C}$ was incubating eggs. MC was agitated by the presence of Pair D, and did not feed his mate as frequently as did other males; instead, he spent much time singing and scolding near the prospective nest site of Pair D. After Pair D disappeared on 25 June, without having laid eggs, MC fed FG more frequently, and she neither called as loudly nor as often as earlier.

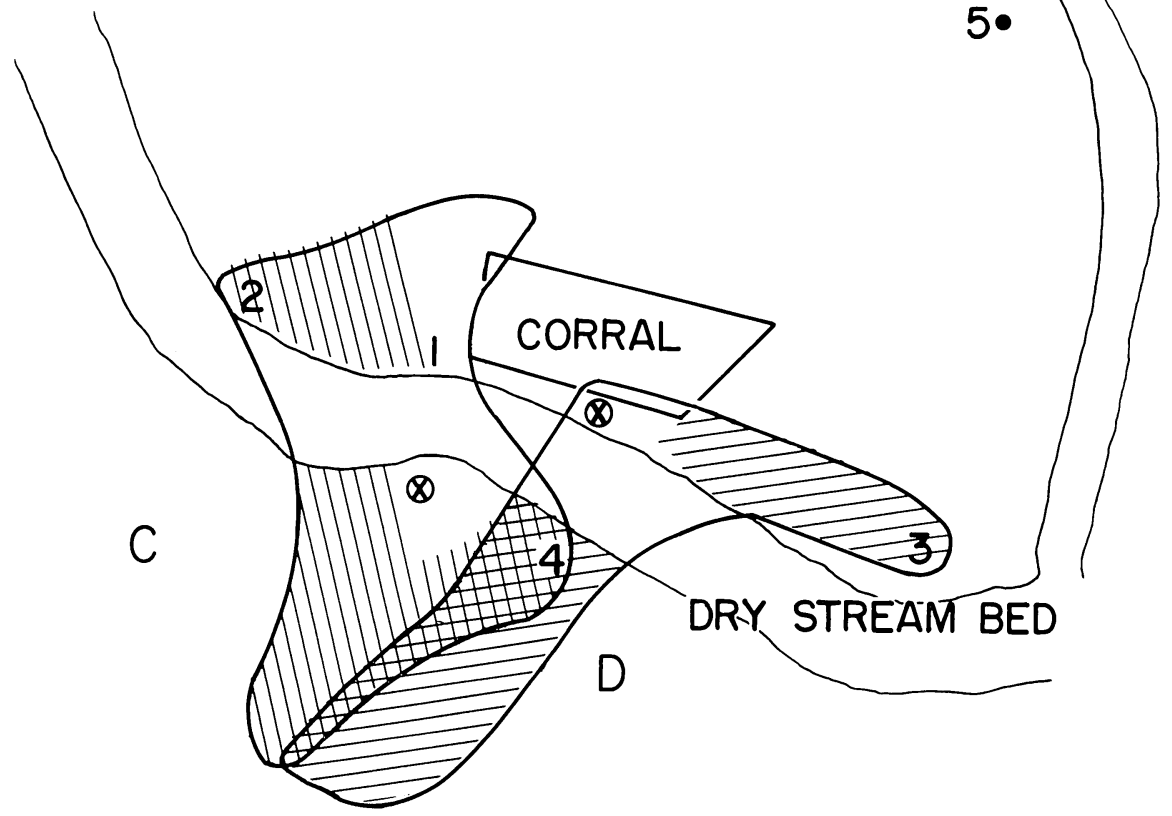

Fig. 10. Territories of two pairs of Elf Owls, C and D. The details of this situation and an explanation of the numbers are given in the text. Circled $\mathrm{X}$ indicates nest site. The hatched areas were used by each pair for foraging, and the crosshatched area was used by both pairs. Scale: 1 inch to 115 feet.

Pair D apparently had moved into the territory of Pair C, possibly because of an available nest site, but either because of the lateness of the season or the activities of MC, did not breed successfully.

FoOd AND Territoriality.-Food appears to be superabundant on the oak-covered hillsides where the owls forage. Even so, each foraging area is generally used by only one pair of owls. The only observed regular 
exception to this was the case described above (Fig. 10), where Pairs C and D utilized the same area in part. Separation of foraging areas is sometimes a result of topography and the resulting vegetation adjacent to the nest site. Figure 11 illustrates this situation. Foraging areas may not be defended as such, but they are usually close to the nest tree and it is difficult to determine what is the object of defense. The foraging areas may be important in the maintenance of the pair bond, as the male feeds and copulates with the female here as well as in the nest tree.

Territorial Conflicts.-Three areas containing from two to four nest sites of Elf Owls were mapped. Two of these are illustrated by Figures 10 and 11 . In the third, the territories were not closely spaced, and no interactions were observed other than those stimulated artificially by the use of the tape recorder. Elf Owl territories appeared to be stable in size from the time the study began in mid-May, until its termination in early August. Territories were determined by marking the most distant points either member of each pair was observed from its respective nest tree.

Males $\mathrm{E}$ and $\mathrm{F}$ of Figure 11 interacted periodically throughout the breeding season. Foraging was almost exclusively on the oak-covered hillsides, thus the likelihood of chance interactions of these pairs at the junction of their territories was small. The first observed territorial interaction, during which both males sang from the same tree, took place on 23 May, and is indicated by number 1. Other observed territorial encounters took place on 6 June (2 and 3) and on 30 July (4). On each occasion the two males sang from the same tree or adjacent trees. In some cases sharp scolds and chases occurred whereas in others one bird simply left. The bird that first retreated was judged to be the loser. For purposes of identification it was followed back to its own nest tree. At points 1, 2, and 3 , male $\mathrm{F}$ was the victor. Why male $\mathrm{E}$ penetrated so far into the territory of $\mathrm{F}$ (points 1 and 3) is unknown. Male F's singing from points 5 and 6 elicited no response from $\mathrm{E}$ on the nights of 10 and 14 June, but F's advance to point 4 on 30 July ended in his retreat to his undisputed territory, from where he continued to sing.

Figure 10 illustrates the territories of two pairs described above. Much of male C's song was from site 1 , whereas most of the song of D was from his nest tree and point 3. The song from the latter site was apparently in response to a third bird whose territory is not shown on the map, and whose nest was several hundred feet from that of Pair D. Although both pairs foraged on the oak-covered hillside, I did not observe members of the two pairs there simultaneously. Female $\mathrm{C}$ foraged on at least two occasions in an insect-rich oak indicated by 4 , as did both members of Pair D. Pair $\mathrm{C}$ also foraged in the area indicated by 2 , and Male $\mathrm{C}$ roosted at point 5 , across an open field from the nest site. 


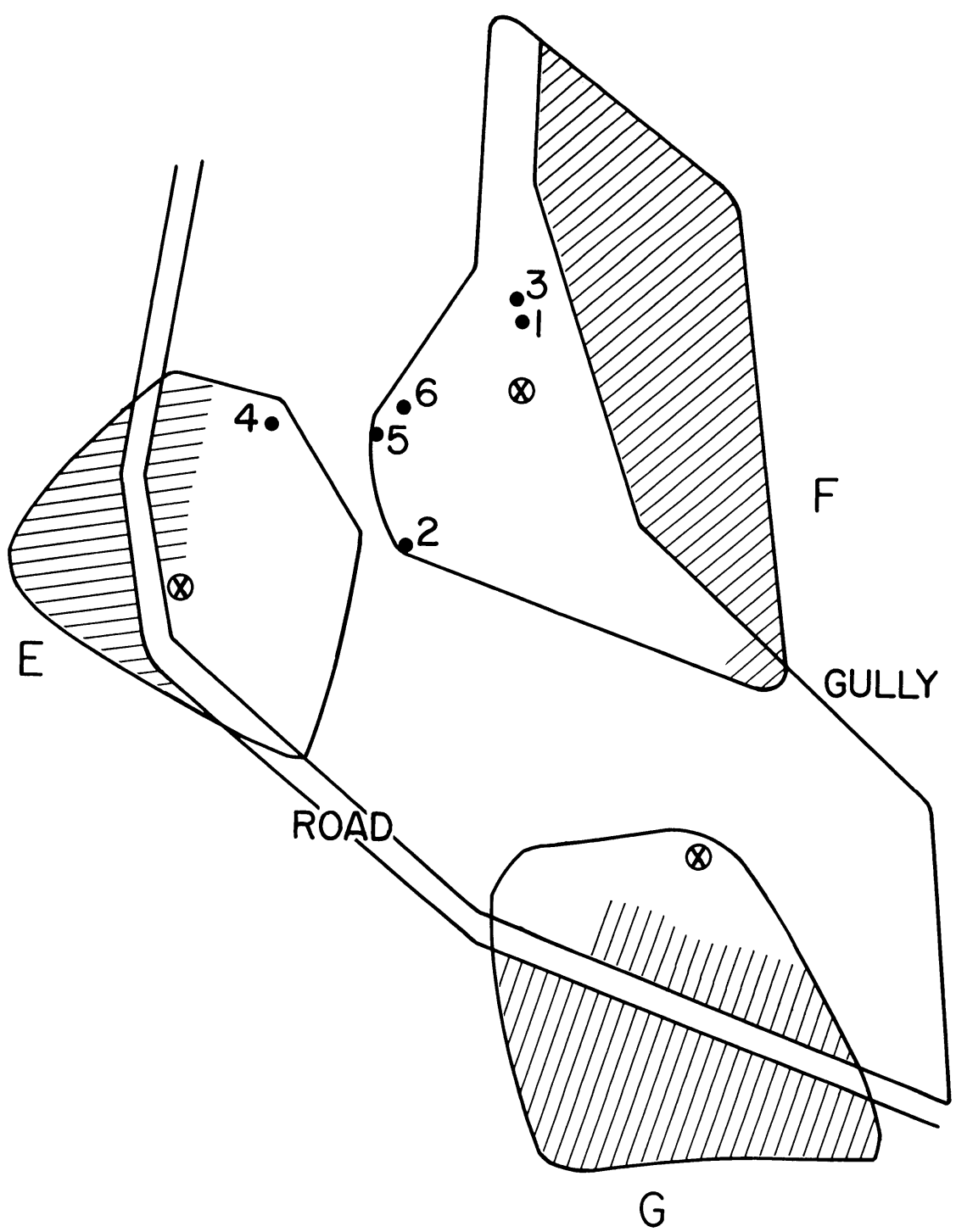

FIG. 11. Territories of three pairs of Elf Owls. Circled $\mathrm{X}$ indicates nest site of each of the pairs (E, F, and $G$ ). Numbers 1-4 indicate sites of territorial encounters between males $\mathrm{E}$ and $\mathrm{F}$. Numbers 5 and 6 are sites of song used by male $\mathrm{F}$ that elicited no response from male $\mathrm{E}$. The dates corresponding to each number are given in the text. Hatched areas indicate the foraging sites of each pair on oak-covered hillsides. Scale: 1 inch to $66 \mathrm{fect}$. 
Draline in Territoriality.-Several authors, including Brewster (1883), have mentioned either finding several adult Elf Owls together or the apparent absence of territoriality in this species (Walker, 1943). On one occasion (15 July 1964) I saw three or four adults in the same small tree, near a nest containing young 18 days old. Two of these adults appeared by their calls to be females.

As territoriality probably functions primarily in formation and maintenance of the pair bond during the early part of the breeding cycle, it would not be surprising to see it wane in mid-summer.

Territoriality in Other Owls.-Territoriality has been studied in at least three other species of owls, Tawny (Southern, 1954), Great Horned, Bubo virginianus (Baumgartner, 1939), and Flammulated (Marshall, 1939). Southern (1954) postulated that the high degree of territoriality in the Tawny Owl made it possible for the birds to learn thoroughly, and therefore to hunt most efficiently in, their permanent territories. The Great Horned Owl's territory appears to be primarily important in breeding (Baumgartner, 1939), as is true of that of the Flammulated Owl (Marshall, 1939).

\section{METABOLISM AND TEMPERATURE REGULATION}

MEASUREMENTS OF MICROCLIMATE AND BODY TEMPERATURE IN NATURE

Nest Cavity Temperature and Humidity.-Temperatures of a few nests were taken to determine some aspects of the microclimate in which juvenal Elf Owls and their female parent live. In two nests in Cave Creek Canyon in 1965 they were recorded continuously from 7 June to 18 July and from 2 June to 1 July, respectively. The highest canyon temperatures for 1965 were recorded during this time. Nest temperatures ranged from $12^{\circ}$ to $31^{\circ} \mathrm{C}$. In one nest the highest daily temperatures were recorded in late afternoon, whereas in the other they were recorded at mid-morning, a result of the different times of day the two cavities were exposed to the direct rays of the sun. Both nests were in rotten portions of living sycamore trunks and were shaded much of the time.

On four occasions temperatures were recorded at a nest near the mouth of Cave Creek Canyon, with a Yellow Springs Telethermometer unit. Unlike the nest cavities mentioned above, this hole was in a dead sycamore limb and completely unshaded. Also, ambient temperatures at the canyon mouth tended to be considerably higher than those recorded in the canyon proper. Thermistor probes, attached to 75 -foot leads, were placed in the cavity above the owls, on the cavity bottom below the owls, and on two occasions, in the cloaca of either the adult female or the single nestling. (When recording continuous body temperature, the probe was inșerted 
into the cloaca and firmly tied to the bases of the rectrices.) The maximum temperature recorded $\left(40^{\circ} \mathrm{C}\right.$ on 29 June) is close to the highest temperatures, $41^{\circ} \mathrm{C}$, recorded in saguaro cactus cavities by Soule (1964), and indicates that upper extremes of temperature in cavities utilized by the Elf Owl in the desert and in the lower portions of the mountain canyons are similar. Ambient temperatures range higher in the desert, but nests there receive protection from the greater insulative capacity of the saguaros. The temperature in the cavities in sycamores drops rapidly in late afternoon, in contrast to the situation in saguaro cavities where temperature continues to rise at this time of day as a result of the slow conduction of heat by the cactus tissue (Soule, 1964).

Relative humidities inside and outside occupied nest cavities were determined on three occasions in Cave Creek Canyon with the use of a Thermistor Psychrometer. Cavity humidities were 16, 22, and 26 per cent, and corresponding ambient humidities were 12, 17, and 21 per cent, respectively. Soule's (1964) values for saguaro cavities range from 27 to 40 per cent, but he informs me (in litt.) that his values probably are too high. Mid-June ambient humidities of the Tucson area often are as low as 10 per cent.

Body Temperature.-The body temperature of an adult female, recorded at 15-minute intervals from 11:00 A.M. to 4:00 P.M. on 20 June, ranged from 37.0 to $39.7^{\circ}$ C. Eleven values of body temperature of adult female Elf Owls were obtained with a mercury thermometer especially designed for small animal work. They ranged from $38.5^{\circ}$ to $40.8^{\circ} \mathrm{C}$ (mean $39.5^{\circ} \mathrm{C}$ ) and were obtained at various times from 8:45 A.M. to 5:50 P.M. The highest was taken at 2:30 P.M.; air temperature inside the cavity was $38.2^{\circ} \mathrm{C}$. The lowest was taken at 5:50 P.M. and air temperature at the cavity entrance was $22.4^{\circ} \mathrm{C}$.

Fluctuation of Body Temperature in Juveniles.-Continuous body temperatures of two young, their nest cavity, and ground level temperatures were recorded on 23 and 26 July 1965. This cavity was in a living sycamore limb. The young were 28 days old, of fleclging age, on the latter date; their body temperatures were relatively constant $\left(36.8-39.6^{\circ} \mathrm{C}\right.$ in a 22 -hour period) and similar to those of adults in the laboratory at comparable ambient temperatures. However, two days earlier, both underwent a period of reduction in body temperature near midday and again in late afternoon prior to the time they were first fed. The body temperatures of these two birds are compared with that of a 19-day-old nestling in a warmer cavity, with its female parent present (Table 7 ). The younger bird shows a more nearly constant body temperature, presumably as a result of the presence of its parent. 
TABLE 7

Nest Cavity and Body Temperatures in ${ }^{\circ} \mathrm{C}$ of Nestling Elf Owls in Two Nests

\begin{tabular}{|c|c|c|c|c|c|}
\hline \multirow[b]{2}{*}{ Time } & \multicolumn{3}{|c|}{ Adult Absent } & \multicolumn{2}{|c|}{ Adult Present } \\
\hline & $\mathrm{T}_{\mathrm{env}}$ & $\mathrm{T}_{\mathrm{B}}$ & $\mathrm{T}_{\mathrm{B}}{ }^{1}$ & $\mathrm{~T}_{\mathrm{cav}}$ & $\mathrm{T}_{\mathrm{B}}{ }^{2}$ \\
\hline 1015 & 22.9 & 36.0 & 35.0 & - & - \\
\hline 1045 & 24.9 & 32.0 & 34.3 & - & - \\
\hline 1115 & 25.5 & 33.0 & 33.0 & 27.3 & - \\
\hline 1145 & 25.8 & 28.2 & 30.6 & 28.7 & 39.0 \\
\hline 1215 & 26.0 & 29.2 & 30.0 & 31.0 & 36.0 \\
\hline 1245 & 27.0 & 29.0 & 30.5 & 31.0 & 37.0 \\
\hline 1315 & 27.3 & 30.5 & 37.0 & 32.2 & 38.6 \\
\hline 1345 & 26.8 & 34.0 & 30.8 & 31.1 & 38.4 \\
\hline 1415 & 26.6 & 36.0 & 31.6 & 32.4 & 37.0 \\
\hline 1445 & 26.5 & 34.5 & 36.3 & 33.5 & 37.1 \\
\hline 1515 & 27.1 & 34.7 & 37.0 & 31.5 & 38.0 \\
\hline 1545 & - & -- & - & 32.5 & 38.8 \\
\hline 1615 & 27.3 & 38.0 & 37.5 & 29.0 & 39.0 \\
\hline 1645 & 27.0 & 36.5 & 36.0 & 27.7 & 38.1 \\
\hline 1715 & 26.2 & 35.0 & 35.8 & 26.0 & 38.0 \\
\hline 1745 & 25.8 & 34.0 & 34.7 & - & - \\
\hline 1815 & 25.2 & 31.0 & 31.3 & - & - \\
\hline 1845 & 25.2 & 32.0 & 32.0 & - & - \\
\hline 1915 & 23.5 & 28.7 & 34.0 & - & - \\
\hline 1945 & 23.5 & 35.5 & 35.0 & - & - \\
\hline
\end{tabular}

1 Two nestlings, 25 days of age.

2 One nestling, 19 days of age.

On 28 June, at 2:50 P.M., the single young (two days old) in a nest was not under its parent, as was typically the case, but was on her back and partly supported by the cavity wall. Temperature in the cavity ranged from 36.8 to $38.0^{\circ}$ C. Both birds were in contact with the cavity on the side opposite the sun. They appeared to move with the sunlight, remaining close to the cavity side opposite it.

Newly hatched Elf Owls are capable of vigorous gular fluttering; this was observed on several occasions immediately upon placing them in the sunlight. This, and to a greater extent behavioral adjustments like those mentioned above, probably serves to regulate the body temperature of small young at high ambient temperatures, while the essentially continuous presence of the parent does so under cooler conditions.

\section{LABORATORY INVESTIGATIONS}

Temperature relations of the Elf Owl were investigated in the laboratory. Where pertinent, data of a similar kind obtained from three other 
species of small owls, Screech, Whiskered, and Saw-whet, are referred to, and a few tentative conclusions regarding the physiology of owls as a group are presented.

The seven Elf Owls used in the laboratory were obtained in the Chiricahua Mountains during the summer of 1965. All were taken from nests shortly before they fledged.

Laboratory Procedures.-The owls were housed in wire-mesh cages in a room at the University of Michigan Museum of Zoology, where air temperature was maintained at $23^{\circ} \mathrm{C}$ and relative humidity ranged from 15 to 50 per cent. Photoperiods matched those prevailing for the latitude of Ann Arbor (about $42^{\circ} \mathrm{N}$ ). The Elf Owls were fed live crickets obtained from a commercial hatchery. All the birds were in good condition throughout the period in which experiments were conducted and had completed the postjuvenal molt before investigations were begun.

All measurements were made during the day and food was withheld on the night preceding each test. Each bird was weighed to the nearest tenth of a gram prior to metabolic measurements.

For measurements of oxygen consumption each owl was placed in a new one-gallon paint can where it perched on a horizontal platform of one-fourth-inch wire mesh. Each chamber was equipped with fittings for tygon tubing connections and an airtight port for a thermocouple. The chambers were placed in a thermostatically controlled temperature cabinet. The air temperature inside each chamber was monitored with a thermocouple used in conjunction with a suitably calibrated Brown Recording Potentiometer. A Beckman Paramagnetic Oxygen Analyzer (Model G-2) equipped with another chart recorder provided essentially continuous records of the oxygen consumption of individual owls. Air flowed from a low pressure line through a tube containing a water absorbent (Drierite) and then through a rotameter for measuring flow rate before entering the animal chamber. Values for oxygen consumption were calculated from flow rates and oxygen concentrations using the appropriate formula given by Depocas and Hart (1957). All values specified for oxygen consumption refer to dry gas at standard conditions of temperature and pressure $\left(0^{\circ} \mathrm{C}\right.$ and $760 \mathrm{~mm} \mathrm{Hg}$ ). Carbon dioxide was removed before the air entered the analyzer.

The animals were placed in the chambers between 8:00 and 9:00 A.M. EST. The first resting rates usually were taken about two hours later, well after the animals had come to rest. With few exceptions, metabolic measurements were taken at three or fewer ambient temperatures per day, and the animals were exposed to a given ambient temperature for at least two hours. Each experiment started at moderate temperatures and moved either to higher or lower temperatures in a stepwise fashion. 
Evaporative water loss was determined by inserting a series of three $\mathrm{U}$ tubes, filled with Drierite, into the exit air flow line from the metabolic chamber. Their change in weight over a carefully measured period of time was taken as the evaporative water loss. During determinations of evaporative water loss, metabolism was recorded every two and one-half minutes rather than every ten minutes, as was the case at other times. Mineral oil was placed under the wire-mesh platforms to trap feces voided by the birds. The air flow for evaporative water loss experiments was $830 \mathrm{cc} / \mathrm{min}$, with one exception. In measuring evaporative water loss at high ambient temperatures $\left(45.0^{\circ} \mathrm{C}\right)$, the flow rate was increased to $1262 \mathrm{cc} / \mathrm{min}$ in order to maintain the humidity inside the metabolism chamber at a low level (see Lasiewski et al., 1966).

Body temperatures were taken at the conclusion of each metabolic run, using either a copper-constantan thermocouple or a mercury thermometer especially designed for small animal work. Continuous recordings of deep body temperature over a period of several hours also were taken, as discussed below.

Investigations of heat tolerance and of the effects of differing humidities on evaporative cooling were undertaken using a Hotpack Environmental Chamber (ca. $7^{\prime} 4^{\prime \prime} \times 6^{\prime} 8^{\prime \prime} \times 4^{\prime} 0^{\prime \prime}$ ) in which humidity and temperature were controlled. Values for the former were imprecise, i.e., by setting the wet and dry bulb controls for a relative humidity of 20 per cent I obtained values ranging from 19 to 26 per cent, over the range of temperatures at which the birds were tested, as calculated from the actual wet and dry bulb temperatures. Ambient and body temperatures were recorded continuously using thermocouples attached to a Brown Recording Potentiometer. The thermocouple recording ambient temperature was placed within three inches of the birds. Body temperatures were obtained by placing thermocouples through the cloaca into the large intestine and securing the wire leads to the bases of the rectrices with surgical clips. The birds were then placed in a small $(10 \times 10 \times 10$ inches) wire cage in the constant temperature room and their body temperatures were allowed to reach a stable level before ambient temperatures were increased. In each test I attempted to hold the humidity at a constant level while ambient temperature was varied. Responses to increased temperature at three humidity ranges were investigated: low (19-26 per cent); medium (47-58 per cent); and high (76-89 per cent). Vapor pressure deficits at these humidities, over the temperature ranges studied, were $38-54,16-36$, and 7-14 $\mathrm{mm} \mathrm{Hg}$, respectively.

The effects of increasing temperature on behavioral and postural adjustments and on gular flutter were observed through a small window in the door of the Hotpack unit, through which the observer was inconspicuous to the owls. Rates of gular flutter were obtained both with an electronic 
stroboscope and by direct counting over a period timed with a stopwatch. When rate of gular flutter was being determined stroboscopically it was necessary to enter the room with the owls. This usually delayed the initiation of flutter until body temperature was somewhat higher than that at which this activity usually began. The periodicity of flutter and the duration of each flutter session were recorded on a revolving kymograph drum by activating a signal magnet connected to an inductorium.

Gular fluttering appeared to be stressful to the owls, and during measurements of it ambient temperatures were increased fairly rapidly in order to minimize the total time birds were actively engaged in this activity.

\section{RESULTS}

Oxygen Consumption.-The relationship of oxygen consumption to ambient temperature in the Elf Owl is illustrated by Figure 12. The Elf Owl appears to possess a zone of thermal neutrality, although its limits are not sharply demarked. Values taken from the range of 33 to $38^{\circ} \mathrm{C}$, ambient temperature, were used to calculate the basal metabolic rate, which is $1.01 \mathrm{cc} \mathrm{O}_{2} /(\mathrm{gm} \mathrm{hr})$. A least squares regression was fitted to the points obtained below $27^{\circ} \mathrm{C}$, and the equation describing the slope is $\mathrm{cc}_{2} /(\mathrm{gm} \mathrm{hr})$ $=2.90-0.060 \mathrm{t}$ (where $t$ is the ambient temperature in ${ }^{\circ} \mathrm{C}$ ).

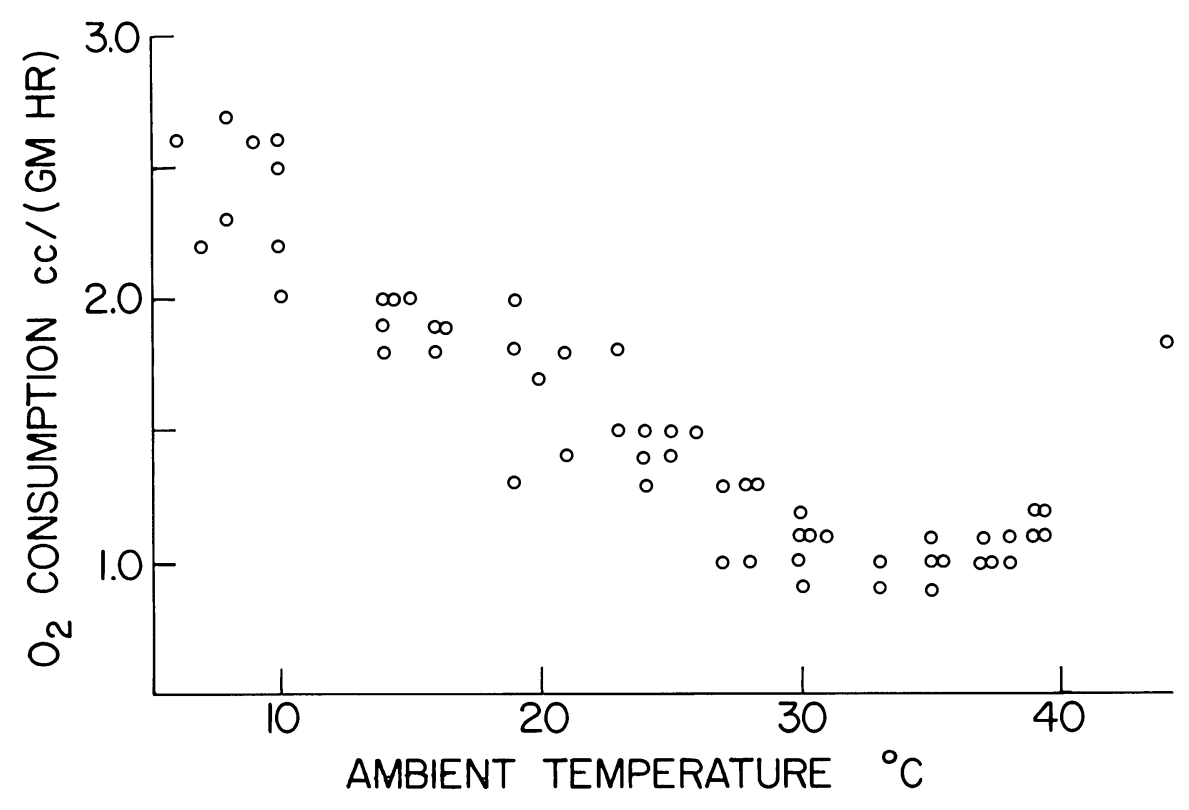

FIc. 12. Resting rate of oxygen consumption of seven Elf Owls in relation to ambient temperaturc, 
Body Temperature.-Body temperatures, taken at the conclusion of metabolic tests at various ambient temperatures, show considerable variation (Fig. 13). This figure reflects the labile nature of body temperature in the Elf Owl.

Evaporative Water Loss.-Figure 14 illustrates the relationship of evaporative water loss to ambient temperature in the Elf Owl. As ambient temperatures exceed a certain level, which is inversely related to the rela-

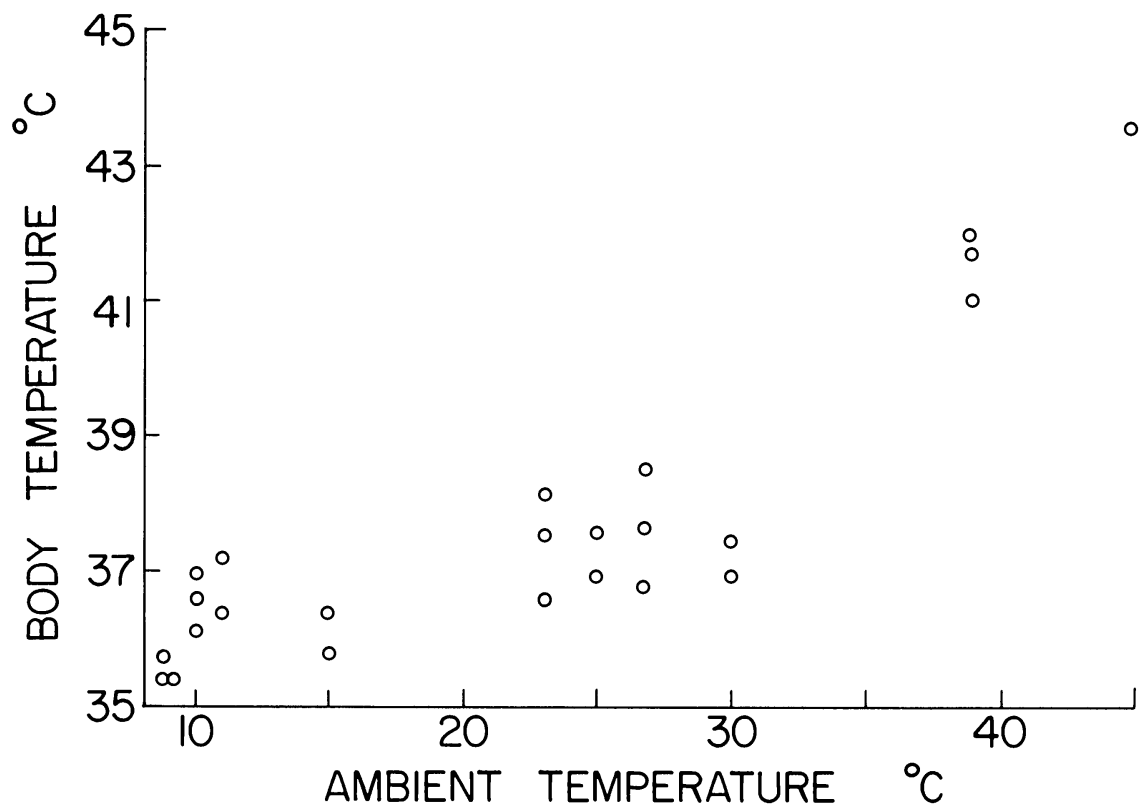

Fig. 13. Body temperature of the Elf Owl as a function of ambient temperature. Relative humidity at $\mathrm{T}_{\mathrm{A}}$ of $45^{\circ}$ was 14 per cent.

tive humidity, active evaporative cooling takes place first by increasing the ventilation of the respiratory tract and then by gular fluttering. These processes are described in detail in a following section. The relative humidity within the metabolism chamber increases as ambient temperatures rise, and the humidity level, along with the ambient temperature, acts to trigger active evaporative cooling. At an ambient temperature $\left(\mathrm{T}_{\mathrm{A}}\right)$ of $45^{\circ} \mathrm{C}$, flow rate was greatly increased, resulting in a relative humidity of about 14 per cent. Table 8 gives relative humidities $(\mathrm{RH})$ in the metabolism chambers at various temperatures, calculated by the equation $\mathrm{RH}=$ $100\left\{\frac{\mathrm{MRT}}{\mathrm{V}(0.621) \mathrm{e}_{\mathrm{s}}}\right\}$ where $\mathrm{M}=\mathrm{gm} \mathrm{H}_{2} \mathrm{O} / \mathrm{min}, \mathrm{V}=\mathrm{cm}^{3}$ air $/ \mathrm{min}, \mathrm{R}=2.87$ $\mathrm{x} 10^{6}$ ergs $/{ }^{\circ} \mathrm{K}, \mathrm{T}={ }^{\circ} \mathrm{K}$, and $\mathrm{e}_{\mathrm{s}}=$ Dynes $/ \mathrm{cm}^{2}$ (Lasiewski, 1964). 
TABLE 8

Relative Humidities at Various Temperatures in Metabolism Chambers

\begin{tabular}{lrrrrrr}
\hline \hline Ambient temperature ${ }^{\circ} \mathrm{C}$ & 30 & 33 & 35 & 37 & 39 & 45 \\
$\begin{array}{l}\text { Flow rate (cc air } / \mathrm{min} \text { ) } \\
\begin{array}{l}\text { Calculated relative } \\
\text { humidity (per cent) }\end{array}\end{array}$ & 830 & 830 & 830 & 830 & 830 & 1262 \\
\hline
\end{tabular}

Responses to Rising Ambient Temperatures.-The initial responses to rising ambient temperatures in the range of $37-44^{\circ} \mathrm{C}$ (responses began at lower $T_{A}$ 's when humidity was high) included cessation of activity and a reduction of insulation afforded by the plumage, through compression of the body feathers. The wings were then held out from the body and the eyes usually were closed. Following these efforts, panting began with conspicuous dorsal-ventral movements of the abdomen. The beak remained closed at this time but the birds swallowed repeatedly, follow-

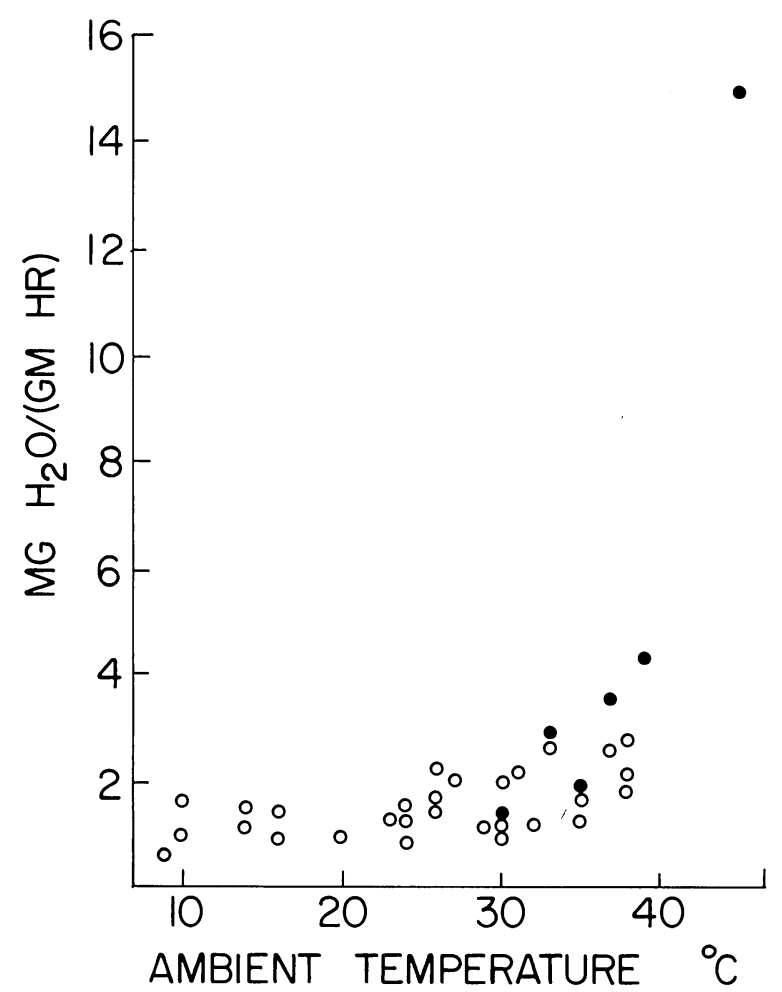

FIs. 14. Evaporative water loss as a function of ambient temperature in the Elf Owl. Solid circles indiçate values for whiçh relative humidities were calculated (Table 8). 
ing this with smacking motions of the beak. If body temperature continued to rise, the birds became restless. Two Elf Owls behaved in an unusual manner; they placed their heads at a bottom corner of the cage and pushed with their feet as if attempting to dig or force their way out.

Gular flutter began at deep body temperatures of between 38 and $41^{\circ} \mathrm{C}$, and at ambient temperatures between 38.5 and $45.0^{\circ} \mathrm{C}$, depending on the humidity. At low and medium humidities, body temperature was maintained below ambient temperatures as high as $45^{\circ} \mathrm{C}$ for short periods. By contrast, at high humidities the birds were unable to remain cooler than the environment. Body temperature varied directly with ambient temperature above $33^{\circ} \mathrm{C}$ at high humidities (Fig. 15).

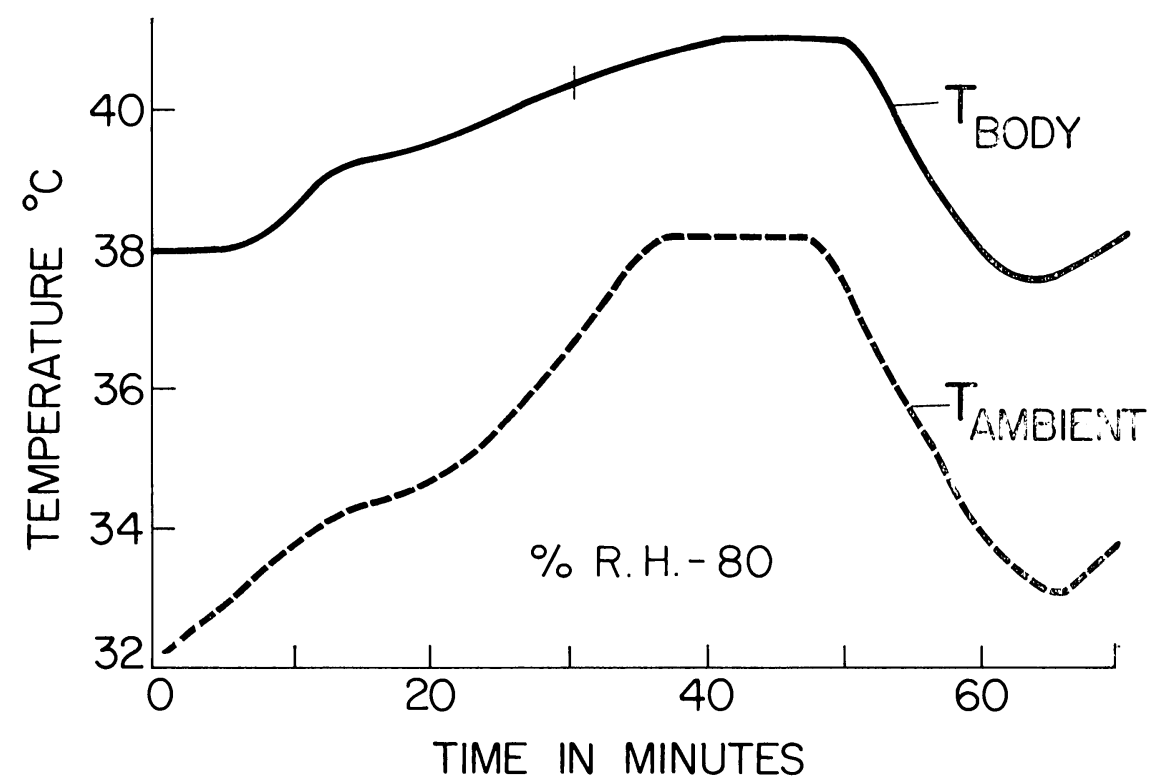

Fig. 15. Cloacal temperature in the Elf Owl in relation to ambient temperature at a relative humidity of about 80 per cent.

Panting rates approached rates of gular flutter; the former ranged from 135 to 160 per minute and the latter from 176 to 523 per minute. Flutter was sometimes preceded by barely perceptible movements of the throat. True gular fluttering usually started at high speed and sometimes slowed conspicuously before cessation, with the beak closing and the throat continuing to move. After a period of gular flutter, the birds often swallowed one or more times. A sticky saliva or mucus accumulated in the mouth during the fluttering; and strands could often be seen adhering to the palate and floor of the pharynx. 
Upper Lethal Body Temperature.-One owl died during the night after having reached a body temperature of $42.3^{\circ} \mathrm{C}$ the previous afternoon; another died a few hours after attaining a maximum body temperature of $42.4^{\circ} \mathrm{C}$. In both cases the birds were obviously strained when removed from the Hotpack unit, but the former appeared to have fully recovered. It had undergone a rise in body temperature to between $41^{\circ}$ and $42^{\circ} \mathrm{C}$ for three 20-minute periods, each separated by more than one hour. The latter owl's body temperature was above $41.5^{\circ} \mathrm{C}$ for only 18 minutes. The body temperature of another individual that was subjected to a $T_{A}$ of $45^{\circ} \mathrm{C}$ for 15 minutes, and fluttered almost continuously during that time, reached $43.6^{\circ} \mathrm{C}$ with no observable ill effects.

\section{DISCUSSION}

Standard Rates of Metabol.ism.-Standard metabolic values for the Elf, Screech, and Whiskered owls, plus that given for an especially low period in the recording of the 24-hour metabolism of the Long-eared Owl (Asio otus) by Graber (1962), were used to determine a metabolismweight curve (Fig. 16). The equation for this curve is $\mathrm{kcal} /$ day $=45.6 \mathrm{~kg}^{0.71}$.

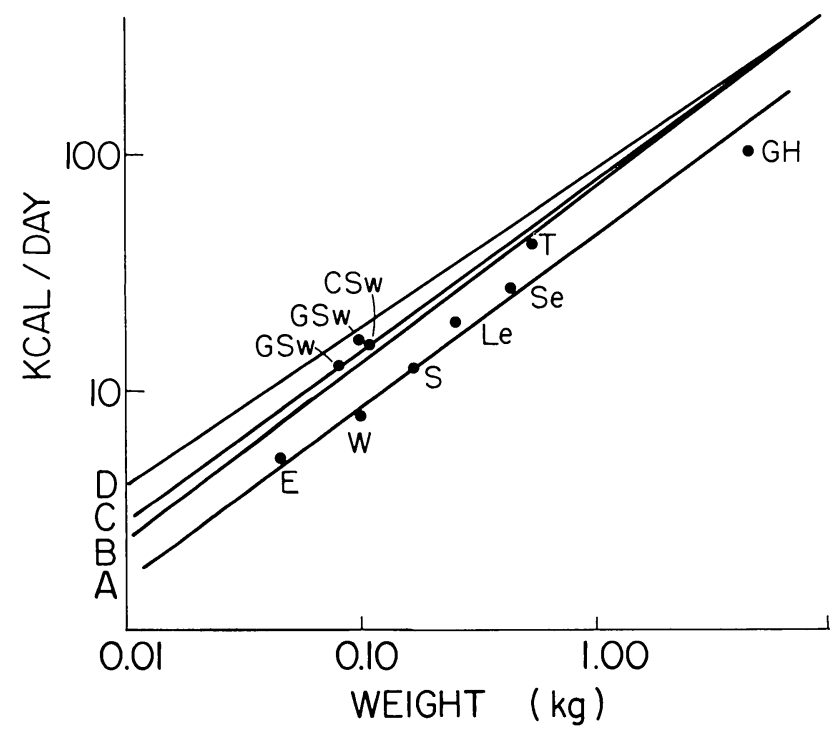

Fig. 16. Relation between standard metabolic rate and body weight in owls (A), compared with: (B) the regression line of King and Farner (1961) for all birds; (C) nonpasserine regression line of Lasiewski and Dawson (1967); and (D) combined passcrine and non-passerine regression line of Lasiewski and Dawson (1967). From the present study: Elf Owl (E), Whiskered Owl (W), and Screech Owl (S). From Graber (1962): Longcared Owl (Le), Short-cared Owl (Asio flammeus) (Se), and Saw-whet Owl (GSw). From King and Farner (1961): Tawny Owl (T), Great Horned Owl (Bubo virginianus) (GH). From Collins (1963): Saw-whet (CSw). Coordinates are logarithmic. 
Other values reported for owls are also plotted in Figure 16. The large difference between the intercept describing the metabolic rate of owls and those attempting to describe either weight-metabolism relationships of birds as a group, or of passerines and non-passerines separately, illustrates the importance of phylogenetic considerations in formulating physiological generalizations (see Lasiewski and Dawson, 1967).

Insulation.-An index of insulation, such as that given by Musser and Shoemaker (1965), $T_{B}-T_{\Lambda} / O_{2}$ consumption, is given in Figure 17 for each of the species of owl that I studied. The Elf and Screech owls maximize

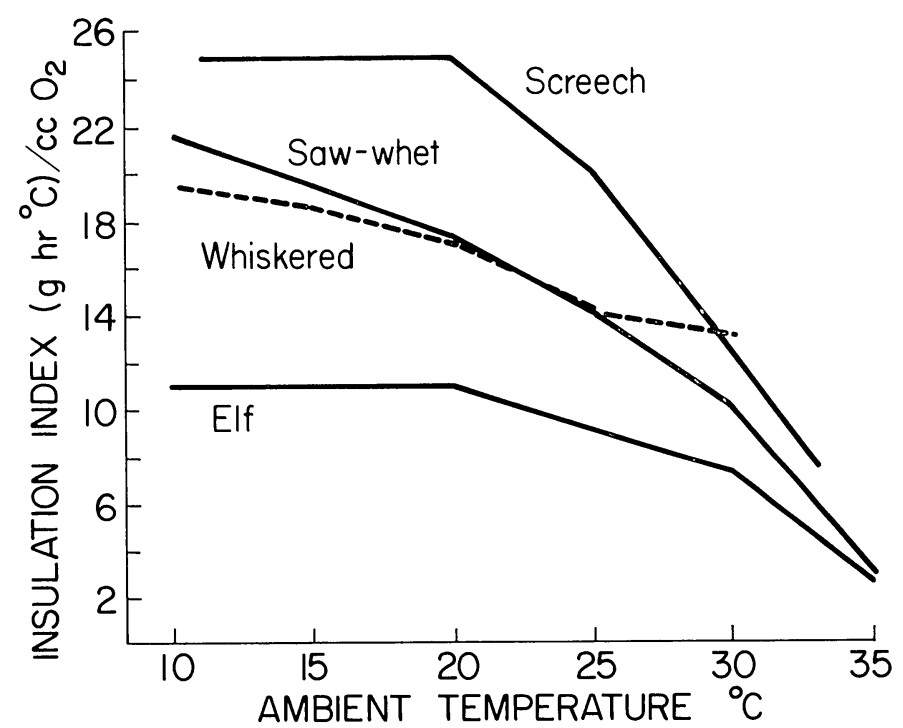

Fig. 17. Index of insulation $\left(\mathrm{T}_{\mathrm{B}}-\mathrm{T}_{\mathrm{A}} / \mathrm{O}_{2}\right.$ consumption) in relation to ambient temperature for four species of owls.

their insulation more rapidly than do the other two species, which combine increasing insulation and metabolism over a wide range of ambient temperatures, as described by West (1962) for several species of passerines. It has been realized for some time that a lower critical temperature, that is, an ambient temperature marking an abrupt transition between regulation of temperature by adjustment of heat production and regulation by adjustment of insulation, does not exist, the transition being gradual instead over a range of several degrees (Dawson, 1958; Dawson and Tordoff, 1959).

Insulation values were calculated for the Elf Owl in the manner described by Misch (1960). The value of $0.30^{\circ} \mathrm{C} \mathrm{x} \mathrm{m}^{2} \times \mathrm{hr} \times \mathrm{kcal}^{-1}$ is lower than for all but one species, a migratory passerine, for which this value has been determined (Misch, 1960). The Elf Owl, too, is migratory and does not give 
the appearance of being well insulated, having bare legs, feet, and eyelids, unlike the other owls studied.

Effectiveness of Evaporative Cooling.-Gular flutter requires very little exertion in some species in which it has been studied, i.e., the Poorwill (Phalaenoptilus nuttallii) and Common Nighthawk (Chordeiles minor) (Bartholomew et al., 1962; Lasiewski and Bartholomew, 1966; Lasiewski and Dawson, 1964). However, this does not appear to be true in the Elf Owl. When the ambient temperature was lowered, following bouts of active evaporative cooling, the birds often slept and body temperatures dropped below usual levels. This was also found to be true in two species of passerines (Dawson, 1954). Gular fluttering seemed to require more effort in some individuals than in others, depending on whether the lower mandible was moved up and down with every flutter.

As demonstrated by Lasiewski et al. (1966), the atmospheric moisture to which it is exposed is very important in determining the ability of the bird to tolerate high ambient temperatures. For this reason experimental conditions during the tests at high ambient temperatures are given in some detail.

At a flow rate of $1262 \mathrm{cc} / \mathrm{min}$-relative humidity 14 per cent-gular flutter was first initiated at a $T_{A}$ of $45^{\circ} \mathrm{C}$. At this low humidity, conditions for effective evaporative cooling should have been optimal. Evaporative water loss and metabolism at a $\mathrm{T}_{A}$ of $45^{\circ} \mathrm{C}$ were measured for a 15 -minute period, after which the owl was removed from the chamber and its $T_{B}$ taken $\left(43.6^{\circ} \mathrm{C}\right)$. The mean evaporative water loss determination (two runs) at an ambient temperature of $45^{\circ} \mathrm{C}$, was $14.95 \mathrm{mg} \mathrm{H}_{2} \mathrm{O} / \mathrm{gm} \mathrm{hr}$. The effectiveness (evaporative water loss/heat produced), assuming that the use of 1 cc of oxygen represents the production of $4.8 \mathrm{cal}$, and that evaporation of $1 \mathrm{mg}$ of water dissipates $0.58 \mathrm{cal}$, is shown in Figure 18. A value of one indicates that all metabolic heat is clissipated through evaporative cooling.

The Poor-will is capable of dissipating about 1.70 times the metabolic heat produced during active evaporative cooling (Bartholomew et al., 1962) whereas the Elf Owl, under similar conditions of ambient temperature and humidity, appears to be capable of clissipating only 0.88 times its metabolic heat produced. Metabolic rate is only slightly increased in the Poor-will during gular flutter, but it is approximately doubled in the Elf Owl. With its less effective evaporative cooling, the Elf Owl becomes conspicuously heated after even a 15-minute exposure to conditions requiring gular flutter. On the other hand, the Poor-will can with little effort maintain a relatively constant body temperature over a long period of time.

Body Temperature and Gular Flutter.-Body and ambient temperatures at which gular flutter was initiated for three humidity ranges are 


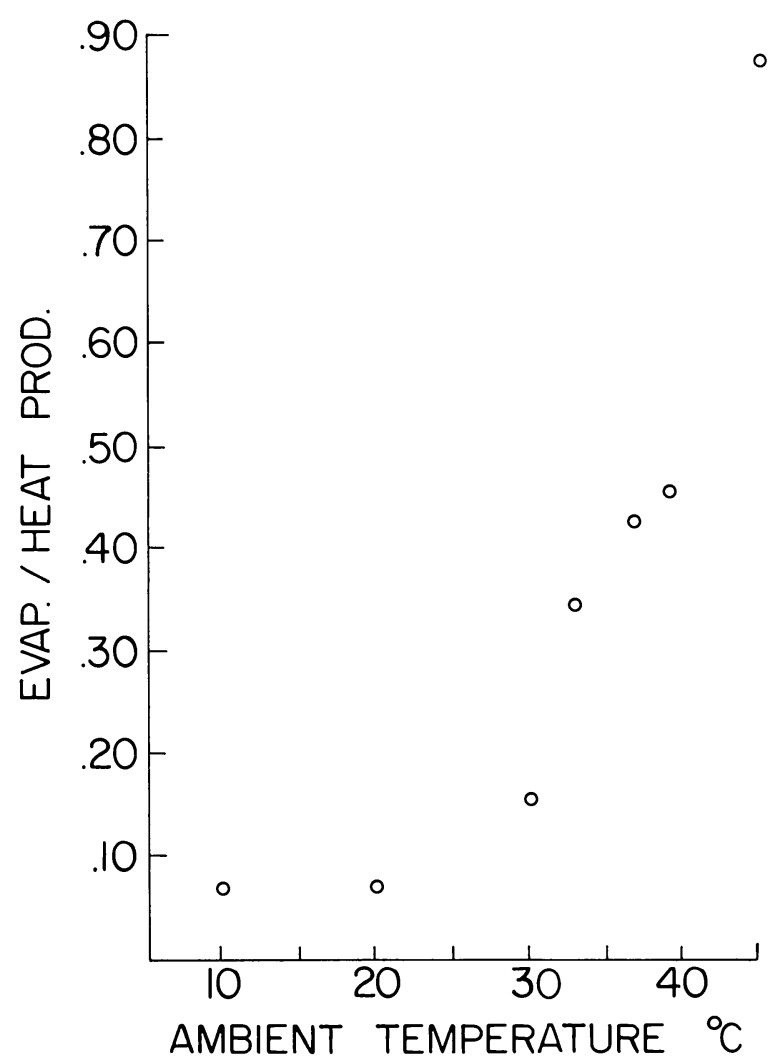

Fig. 18. The relation between heat dissipated through evaporative cooling and heat produced by metabolism as a function of ambient temperature in the Elf Owl.

illustrated in Figure 19. Ambient temperatures were raised at a rate of $1^{\circ} \mathrm{C}$ per 3,5 , and 10 minutes at a relative humidity of 20 per cent; $1^{\circ} \mathrm{C}$ per 6,9 , and 10 minutes at a relative humidity of 50 per cent; and $1^{\circ} \mathrm{C}$ per 6,7 , and 8 minutes at a relative humidity of 80 per cent. The time elapsed between the initial rise in body temperature and first gular flutter was correlated with the level of the body temperature prior to a rise in ambient temperatures. An inverse relationship apparently exists between two factors influencing the onset of gular flutter, ambient temperature, and relative humidity.

At low humidities and at temperatures below $40^{\circ} \mathrm{C}$, postural adjustments, moderate hyperthermia, and especially increased respiratory activity (panting) are effective in maintaining a favorable balance between heat production and loss. At higher humidities these mechanisms are not suffi- 
ciently effective to remove all metabolic heat produced, and at high humidities body temperature rises in parallel with rising ambient temperatures (Figure 15).

\section{CONCLUSIONS DRAWN FROM LABORATORY STUDIES}

Owls as a group possess low basal rates of metabolism as compared with many other birds.

The effectiveness of insulation is an important adaptation to the habitats in which the owls live, being low in the southern and highly migratory Elf Owl and high in the other species studied. The four species appear to respond to decreasing ambient temperature by maximizing insulation

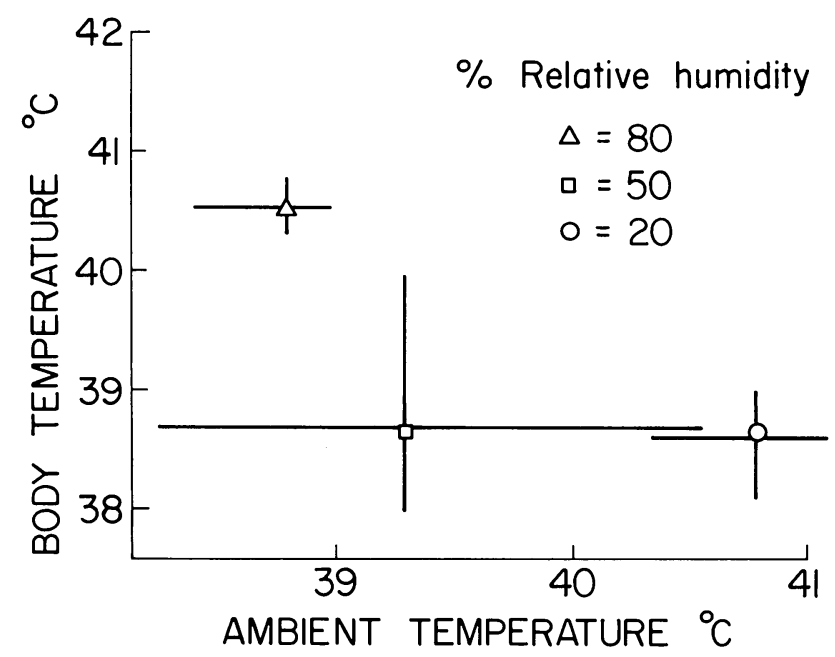

FIG. 19. The ambient and body temperatures at which gular flutter is initiated in the Elf Owl, at three different humidity levels.

relatively rapidly (Elf Owl, Screech Owl) or increasing insulation over a wide range of ambient temperatures (Saw-whet Owl, Whiskered Owl).

The Elf Owl is less effective in dissipating heat through gular fluttering than any caprimulgids that have been studied. At least two factors seem to be involved: the Elf Owl does not possess a large moist surface for evaporative cooling, such as those of the huge-mouthed goatsuckers; gular flutter requires little energy expenditure in the caprimulgids, but in the Elf Owl it increases metabolism to approximately twice the standard rate. Additionally, the owls avoid the heat by nocturnal activity and appropriate choice of microclimate, whereas the two species of caprimulgids that have been studied nest in the open, often directly exposed to the rays of the sun, 


\section{TEMPERATURE RELATIONS UNDER NATURAL CONDITIONS}

Ambient temperatures are not high enough in the mountain canyons to pose a problem to the Elf Owls. However, it is probable in the hot Sonoran Desert that the insulation provided by the saguaro is as important to the owls as the nest sites themselves. Swarth (1905:26) states that the Elf Owls are restricted to the cool depths of the giant cactus. He says further: "The elf owl seems to be strictly nocturnal, and, when turned loose in the glaring sunlight, they were singularly helpless, in striking contrast to the little pigmy owl, which in general appearance, they resemble so much." Bendire (1892:413) notes that Elf Owls "leave the sahuaras and take to the bush" during the rainy season. Bent (1938:442) likewise states that Elf Owls are said to use cavities only in the breeding season (the hottest part of the year).

Conditions of temperature and humidity within saguaro cavities are sufficiently moderate (Soule, 1964) that Elf Owls in them would rarely have to employ gular flutter. The highest cavity temperature recorded by Soule (1964) was $41^{\circ} \mathrm{C}$.

In the desert, both members of a pair are sometimes found in the same cavity (Brandt, 1951; Soule, 1964; other authors). However, in the cooler Chiricahua Mountains, males were never found in nest cavities. At dawn the male owls flew up the canyon sides and passed the day in the thick foliage of oaks or junipers. Here they were shaded and exposed to cooling breezes. The use of cavities by male Elf Owls in the desert thus appears to be a means of avoiding extreme temperatures, a behavioral adaptation to desert conditions.

Conservation of body water might be an additional factor in the use of saguaro cavities by the owls. The Elf Owl has a daily activity pattern similar to that of small fossorial desert rodents. A saguaro cavity provides them with the same kind of advantage in water economy that underground burrows afford small mammals. Humidities in empty saguaro cavities are 4 to 10 per cent higher than ambient values (Soule, 1964), and with one or more owls inside the difference should be even greater, thus reducing the rate of evaporative water loss.

The captive owls remained in good health in the laboratory for more than a year, with no access to water. Like many other predatory birds, they probably never drink in nature; in some cases they live miles from any source of open water. Elf Owls apparently can maintain a favorable water balance on their diet of insects.

The activity and apparent discomfort of Elf Owls prior to and during gular flutter at any humidity suggests that it is rarely used in nature, and that selection of an equable microclimate is the ordinary means of coping with high ambient temperatures. As with most other desert birds which 
have been studied, behavioral avoidance appears to play a major role in adaptation to desert existence (Dawson and Schmidt-Nielsen, 1964).

\section{BEHAVIORAL ATTITUDES}

Concealment.-The Elf Owl stands erect with its feathers compressed when attempting to avoid detection (Figure 20). The erection of the white feathers above the eyes and below the facial disk is conspicuous. In addition, the wing is drawn forward and its white leading edge, and to a lesser degree the scapulars, apparently serve to form a disruptive camouflage. Brewster

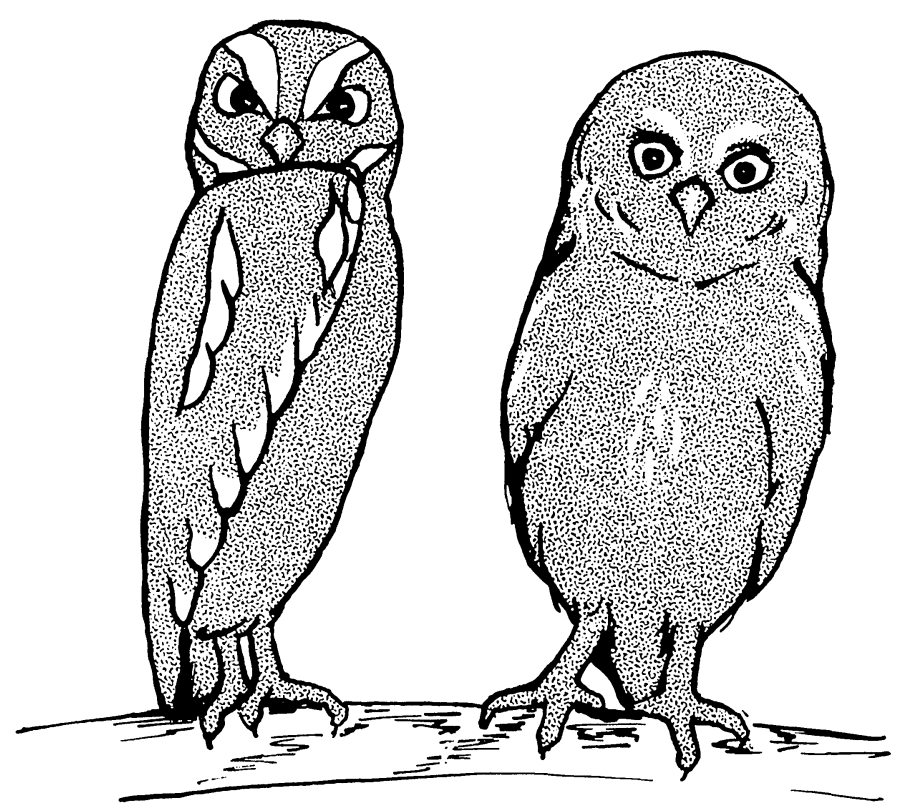

Fis. 20. Erect and relaxed postures of the Elf Owl. The erect posture camouflages the owl.

(1883:28), quoting the field notes of F. Stephens, illustrates its effects: "I discovered a Whitney's Owl sitting on a branch with its side towards me and one wing held up, shield-fashion, before its face. I could just see its eyes over the wing, and had it kept them shut I might have overlooked it, as they first attracted my attention. It had drawn itself into the smallest possible compass, so that its head formed the widest part of its outline. . . whichever way I went the wing was always interposed."

DEFENSE.-When Elf Owls are threatened, they may erect contour feathers of the breast and back, and sway from side to side, occasionally snapping 
their mandibles. The wing or wings may be dropped, but they are not extended in the manner of many other species of owls.

Antagonistic Behavior in Captivity.-Captive Elf Owls sometimes fought mildly when perched close together. Fighting consisted of each bird's biting at the beak of its opponent, interspersed with twittering scold notes.

\section{MOLT}

The information on molt presented here was obtained largely from captive individuals. Some molting specimens taken in the wild also were examined; they indicate that the sequence of feather replacement of the captive birds was normal. Mayr and Mayr (1954) did not examine any molting specimens of Elf Owls in their study of tail molt of small owls.

\section{TIMING OF MOLT}

Molt began in early September in seven captive juveniles, when they were slightly over two months old. A wild juvenile (UMMZ 161965) taken in Arizona on 12 September had not begun molting, while another (UMMZ 125954) taken on 7 September was well underway with its postjuvenal molt. Two Arizona specimens (ARP 2437, 2438) were undergoing a heavy body molt when taken on 22 September. Both had almost completely attained first winter plumage, but each possesses a few feathers that appear to be of the juvenal plumage. The only heavily molting wild adult that I have seen (ARP 3263) was also taken in Arizona, on 23 September. A specimen from Arizona, taken on 20 September (LSU 39936), is said to be in fresh plumage (J. Cracraft, letter 4 November 1965), indicating that it had completed the molt at that time. A specimen taken in Guerrero on 30 November (MVZ 109737) is in fresh plumage with no basal sheaths detected on any body or flight feathers (N. K. Johnson in litt.). Another specimen (ARP 8646) taken in Michoacan in late November had essentially completed the body molt, with only the white-edged scapulars and a few contour feathers of the belly and back still ensheathed.

The above specimens indicate that the annual molt begins in early September in both juveniles and adults and that it continues in some individuals into December.

\section{SEQUENCE OF FEATHER REPLACEMENT}

BoDy.-The information presented here is based on captive individuals whose molt apparently was completely normal. Seven immature Elf Owls were examined on four occasions during their molt: 7 and 21 September; 
18 October; and 9 November. Notes were taken on the condition of each bird. The following is a summary of these observations.

Seven September: Feather replacement began at the leading edges of the wings, with upper lesser coverts being replaced and a development of the first true under-wing coverts. The first greater primary wing coverts also appeared at this time. At this early stage, molt of body feathers was slightly noticeable on some individuals.

Twenty-one September: A row of new feathers on each side of the breast was seen in some individuals. Body molt was heavy, while covert replacement of the wings was largely completed. Molt of the head and facial area had not yet begun.

Eighteen October: Feathers of lower back, flanks, and tarsal bristles were largely in quills. There was heavy molt on the head and facial area, including the "eyelashes." Median coverts of the wing were being replaced.

Nine November: The owls now appeared to be in fresh basic or first winter plumage, although most feathers were still sheathed at the bases. The last regions to undergo molt, and as a consequence the most heavily quilled areas, were the flanks, thighs, crown, and nuchal area. The remiges, greater coverts, and rectrices were not replaced during the postjuvenal molt.

REMIGES.-Primary replacement is sequential from number one (the innermost) to number 11. The molting wild adult from Arizona (ARP 3263) taken on 23 September had seven primaries fully replaced, with the seventh still sheathed at the base, and the eighth had grown to about one quarter of its ultimate length. The greater primary coverts are dropped shortly after their corresponding primaries begin to regenerate.

Based on two captive Elf Owls (age about 14 months) undergoing their first complete molt, the replacement of the first nine secondaries is chronologically as follows: one (the outermost) and five; two and nine; three and six; eight; and four and seven. Secondaries one and five are completely regrown by the time four and seven are lost; the other seven may be ensheathed simultaneously for a short period. Replacement of the inner three secondaries, or tertials, was not recorded.

REcTRICES.--In the Elf Owl, as in many other species of small owls (Mayr and Mayr, 1954; Collins, 1961), the rectrices appear to be lost essentially simultaneously. The molting wild adult (ARP 3263) discussed earlier had the tail almost completely regrown, but all ten rectrices were ensheathed at their bases. Observations on captive birds corroborated an almost simultaneous loss of all rectrices, and indicated that replacement took place within a period of about three weeks. 


\section{SUMMARY}

1. The populations of the Elf Owl included in this study breed in the southern portions of the southwestern tier of states of the United States, in northern Mexico, and in the state of Puebla. I know of no breeding records from central Mexico.

2. Elf Owls migrate to southern Mexico and winter in the Rio Balsas Basin. The winter range is bounded by the Sierra Madre del Sur of Guerrero on the south and the Mexican Plateau on the north. It extends west in to Michoacan, and east probably in to Oaxaca.

3. Vocalizations of male Elf Owls include two distinct songs, which serve different functions. At least two other calls are given by females only.

4. Male Elf Owls appear to arrive on the breeding grounds, locate cavities, and set up territories prior to the arrival of the females.

5. Pair formation appears to take place rapidly, within a single night.

6. Elf Owls are totally dependent on woodpeckers for nest sites. The sites vary greatly in depth, and in height above the ground.

7. Male Elf Owls sing from potential nest sites, attracting their mates to the cavities.

8. Female Elf Owls roost in nest cavities in the daytime for one to two weeks prior to egg-laying.

9. Females are fed by their mates from the time of pair formation until the young are approximately half grown.

10. Typically, eggs are laid on alternate days. In Cave Creek Canyon the most common clutch size was three.

11. Incubation is performed solely by the female and requires 24 days.

12. The female remains in the cavity night and day while the young are small. The male brings food to the cavity entrance, and the female passes it on to the young.

13. Nesting success was extremely high; the only nests lost were a result of interference by the investigator. In the 23 successful nests only two young died of starvation.

14. After the female ceases brooding, the male feeds the young almost exclusively. Feeding rates are highest at dusk and dawn.

15. Elf Owls fledge at an age of 28 to 33 days, when they are capable of flight.

16. Insects form the major food of Elf Owls. Other arthropods, including poisonous scorpions, also are taken. Only two records of vertebrate prey are known.

17. Elf Owls are territorial, but their territories are small and centered about the nest tree.

18. Molt is annual and the rectrices appear to be replaced simultaneously. 
Postjuvenal molt does not include the rectrices or remiges. Molt appears to take place prior to fall migration.

19. The basal or standard metabolic rate of the Elf Owl is $1.01 \mathrm{cc} \mathrm{O}_{2} /$ (gm hr).

20. Body temperature is labile, ranging from $35.4^{\circ}$ to $43.6^{\circ} \mathrm{G}$ over an ambient temperature range of 9 to $45^{\circ} \mathrm{C}$.

21. Humidity is important in the effectiveness of evaporative cooling; effectiveness decreased as humidity increased.

22. In the Elf Owl, gular flutter is one-half as effective in dissipating heat as it is in the two species of goatsuckers that have been studied.

23. The equation describing a metabolism-weight curve for owls is $\mathrm{kcal} /$ day $=45.6 \mathrm{~kg}^{0.71}$.

24. Insulation in the Elf Owl is less than in the other species of owls in which it has been measured.

25. Elf Owls probably rarely utilize gular fluttering in nature. The insulation of cavities in the saguaro cactus probably makes it possible for the Elf Owl to live in deserts without meeting the extremely high temperatures which prevail there seasonally.

\section{LITERATURE CITED}

Allen, A. A. 1924. A contribution to the life history and economic status of the screech owl (Olus asio). Auk, 41:1-16.

American Ornithologists' Union. 1957. Check-list of North American birds. 5th Ed. Baltimore. Amer. Ornith. Union.

Bartholomew, G. A., J. W. Hudson, and T. R. Howfll. 1962. Body temperature, oxygen consumption, evaporative water loss, and heart rate in the poor-will. Condor, $64: 117-125$.

Baumgartner, F. M. 1939. Territory and population in the great horned owl. Auk, $56: 274-282$.

BENDIRE, C. 1892. Life histories of North American birds with special reference to their breeding habits and eggs. Smithsonian Inst., U. S. Natl. Mus. Spec. Bull. 1.

BENT, A. C. 1938. Life historics of North American birds of prey. Part 2. Smithsonian Inst., U. S. Nat. Mus. Bull. 170.

Bergmann, H., And M. Ganso. 1965. Zur Biologic des Sperlingskauzes (Glaucidium passerinum) (L). Jour. für Ornithologie, 106:255-284.

Brandt, H. 1951. Arizona and its bird life. The Bird Research Foundation. Cleveland.

Brewster, W. 1883. On a collection of birds lately made by Mr. F. Stephens in Arizona. Auk, 8:21-36.

Brown, H. 1903. Arizona bird notes. Auk, 20:43-50.

- - 1904. The elf owl in California. Condor, 6:45-47. 
Bruner, S. C. 1926. Notes on the birds of the Baboquivari Mountains, Arizona. Condor, 28:231-238.

Campbell, B. 1934. Bird notes from southern Arizona. Condor, 36:201-203.

Collins, C. T. 1961. Tail molt of the saw-whet owl. Auk, 78:634.

--1963. Notes on the feeding behavior, metabolism, and weight of the saw-whet owl. Condor, 65:528-530.

DAvis, J. 1958. Publications reviewed: Check-list of North American birds. Condor, 60:197-198.

- - 1965. Natural history, variation, and distribution of the Strickland's woodpecker. Auk, 82:537-590.

DAwson, W. R. 1954. Temperature regulation and water requirements of the brown and Abert towhecs, Pipilo fuscus and Pipilo aberti. Univ. Calif. Publ. Zool., 59:81-124.

-- 1958. Relation of oxygen consumption and evaporative water loss to temperature in the cardinal. Physiol. Zool., 31:37-48.

Dawson, W. R., And K. Schmidt-Niflsen. 1964. Terrestrial animals in dry heat: desert birds. In: Handbook of Physiology, sec. 4 (D. B. Dill Ed.). Williams and Wilkens Co., Baltimore. Pp. 481-492.

DAwson, W. R., and H. B. TordofF. 1959. Relation of oxygen consumption to temperature in the evening grosbeak. Condor, 61:388-396.

Depocas, F., And J. S. Hart. 1957. Use of the Pauling oxygen analyzer for measurement of oxygen consumption of animals in open-circuit systems and in a short-lag, closed circuit apparatus. Jour. Appl. Physiol., 10:388-392.

Dixon, K. L. 1959. Ecological and distributional relations of desert scrub birds of western Texas. Condor, 61:397-409.

Fowler, F. H. 1903. Stray notes from southern Arizona. Condor, 5:106-107.

Graber, R. R. 1962. Food and oxygen consumption in three species of owls (Strigidac). Condor, 64:473-487.

HAFtoRn, S. 1966. Egglegging og ruging hos meiser basert på temperaturmålinger og direkte iakttagelser. Sterna, 7:49-102. .

Hanna, W. C. 1935. Whitney's elf owl. Oologist, 52:102-103.

Haverschmidt, F. 1946. Observations on the breeding of the little owl. Ardea, 34:214-246.

Hinde, R. A. 1956. The biological significance of territories of birds. Ibis, 98:340-369.

Howel. A. B. 1916. Some results of a winter's observations in Arizona. Condor, 18:209-214.

Howell, A. B., ANd A. J. van Rossem. 1915. Additional observations on the birds of the lower Colorado Valley in California. Condor, 17:232-234.

James, P., AND A. Hayse. 1963. Elf owl rediscovered in lower Rio Grande Delta of Texas. Wilson Bull., 75:179-182.

Jansson, E. 1964. Anteckinger rörande häckande sparvuggla (Glaucidium passerinum). Vår Fi̊gelvärld, 23:209-222. 
King, J. R., AND D. S. FARner. 1961. Energy metabolism, thermoregulation and body temperature. In: Biology and Comparative Physiology of Birds. Vol. II (A. J. Marshall, Ed.), Academic Press. Pp. 215-288.

Kluijver, H. N. 1951. The population ecology of the great tit, Parus m. major L. Ardea, 39:1-135.

KoniG, C. 1965. "Zeigen” der Bruthöhle bei Sperlingskauz (Glaucidium passerinum) und Zwergohreule (Otus scops). Jour. für Ornithologie, 106:349-350.

LACK, D. 1954. The natural regulation of animal numbers. Clarendon Press, Oxford.

- - 1966. Population studies of birds. Ibid.

LAsiewski, R. C. 1964. Body temperature, heart and breathing rate, and evaporative water loss in hummingbirds. Physiol. Zool., 37:212-223.

Lasiewski, R. C., A. L. Acosta, and M. H. Bernstein. 1966. Evaporative water loss in birds-I. Characteristics of the open flow method of determination, and their relation to estimates of thermoregulatory ability. Comp. Biochem. Physiol., 19:445-457.

Lasiewski, R. C., And G. A. Bartholomew. 1966. Evaporative cooling in the poor-will and tawny frogmouth. Condor, 68:253-262.

LASIEWSKI, R. C., AND W. R. DAWSON. 1964. Physiological responses to temperature in the common nighthawk. Condor, 66:477-490.

- - 1967. A re-examination of the relation between standard metabolic rate and body weight in birds. Condor, 69:13-23.

Ligon, J. S. 1961. New Mexico birds and where to find them. Univ. New Mexico Press, Albuquerque.

Marshall, J. T., JR. 1939. Territorial behavior in the flammulated owl. Condor, 41:71-78.

--1957. Birds of pinc-oak woodland in southern Arizona and adjacent Mexico. Pac. Coast Avifauna, 32:1-125.

MAYr, E., AND M. MAYr. 1954. The tail molt of small owls. Auk, 71:172-178.

Miller, A. H. 1955. The avifauna of the Sicrra del Carmen of Coahuila, Mexico. Condor, 57:154-178.

Miller, L. 1946. The elf owl moves west. Condor, 48:284-285.

Misch, M. S. 1960. Heat regulation in the northern blue jay, Cyanocitta cristata bromia Oberholser. Physiol. Zool., 33:252-259.

Muir, R. C. 1954. Calling and fecding rates of fledged tawny owls. Bird Study, 1:111-117.

Musser, G. G., AND V. H. Shoemaker. 1965. Oxygen consumption and body temperature in relation to ambient temperature in the Mexican deer mice, Peromyscus thomasi and $P$. megalops. Occ. Papers Mus. Zool. Univ. Mich. 643:1-15.

NicE, M. M. 1957. Nesting success in altricial birds. Auk, 74:305-321.

Norburg, A. 1964. Studier över pärlugglans (Aegolius funereus) ekologi och etologi. Vår Fågelvärld, 23:228-244, 
Northern, J. R. 1965. Notes on the owls of the Tres Marias Islands, Nayarit, Mexico. Condor, 67:358.

Phildips, A. R. 1942. Notes on the migrations of the elf and flammulated screech owls. Wilson Bull., 54:132-137.

Phillips, A. R., J. T. Marshall, Jr., and G. Monson. 1964. The birds of Arizona. Univ. Arizona Press, Tucson.

Pough, R H. 1957. Audubon western bird guide. Natl. Aud. Soc., Doubleday and Co., Garden City, New York.

Quir.t.IN, R. W. 1935. New bird records from Texas. Auk, 52:324-325.

Santee, R., AND W. Grenfield. 1939. Behavior of the saw-whet owl on its nesting grounds. Condor, 41:3-9.

Scotr, W. E. D. 1886. On the avi-fauna of Pinal County, with remarks on some birds of Pima and Gila counties, Arizona. Auk, 3:421-432.

Sherman, A. P. 1911. Nest life of the screech owl. Auk, 28:155-168.

Smith, A. P. 1907. Summer notes from an Arizona camp. Condor, 9:196-197.

Soule, O. H. 1964. The saguaro tree-hole microenvironment in southern Arizona. II. Summer. Unpubl. M. S. thesis, Univ. of Arizona.

Southern, H. N. 1954. Tawny owls and their prey. Ibis, 96:384-410.

Sutron, G. M. 1943. Records from the Tucson region of Arizona. Auk, 60:345-350.

Swarth, H. S. 1905. Summer birds of the Papago Indian Rescrvation and of the Santa Rita Mountains, Arizona. Condor, 7:22-28.

TANner, J. T. 1966. Control of the initiation of egg laying in temperate zone birds. In: Abstracts Congressus Internationalis Ornithologicus. Pp. 111-112. (Used with permission of author)

Van Tyne, J., And G. M. Sutton. 1937. The birds of Brewster County, Texas. Misc. Publ. Mus. Zool. Univ. Mich., 37:1-119.

von HaArtman, L. 1956. Territory in the pied flycatcher, Muscicapa hypoleuca. Ibis, $98: 460-475$.

-_-1957. Adaptation in hole-nesting birds. Evol., 11:339-347.

WALKer, L. W. 1943. Nocturnal observations of elf owls. Condor, 45:165-167.

Welty, J. C. 1962. The life of birds. W. B. Saunders Co., Philadelphia and London.

West, G. C. 1962. Responses and adaptations of wild birds to environmental temperature. In: Comparative Physiology of Temperature Regulation (J. P. Hannon and E. Viereck Eds.), part 3. Arctic Acromed. Lab., Ft. Wainwright, Alaska. Pp. 291-333.

Willard, F. C. 1912. A week afield in southern Arizona. Condor, 14:53-63.

Accepted for publication September 22, 1967 



